\title{
Power Maximization and Turbulence Intensity Management through Axial Induction-Based Optimization and Efficient Static Turbine Deployment
}

\author{
Mfon Charles ${ }^{1, *(\mathbb{D})}$, David T. O. Oyedokun ${ }^{1}$ and Mqhele Dlodlo ${ }^{1,2} \mathbb{D}$ \\ 1 Department of Electrical Engineering, University of Cape Town, Rondebosch, Cape Town 7700, South Africa; \\ david.oyedokun@uct.ac.za (D.T.O.O.); mqhele.dlodlo@uct.ac.za (M.D.) \\ 2 Vice-Chancellor's Department, National University of Science and Technology (NUST), Corner, Gwanda \\ Road and Cecil Avenue, Bulawayo P.O. Box AC939, Zimbabwe \\ * Correspondence: chrmfo001@myuct.ac.za; Tel.: +27-7354-404-50
}

check for updates

Citation: Charles, M.; Oyedokun, D.T.O.; Dlodlo, M. Power

Maximization and Turbulence

Intensity Management through Axial Induction-Based Optimization and Efficient Static Turbine Deployment. Energies 2021, 14, 4943. https:// doi.org/10.3390/en14164943

Academic Editor: Pavlos S Georgilakis

Received: 30 June 2021

Accepted: 2 August 2021

Published: 12 August 2021

Publisher's Note: MDPI stays neutral with regard to jurisdictional claims in published maps and institutional affiliations.

Copyright: (c) 2021 by the authors. Licensee MDPI, Basel, Switzerland. This article is an open access article distributed under the terms and conditions of the Creative Commons Attribution (CC BY) license (https:/ / creativecommons.org/licenses/by/ $4.0 /)$.

\begin{abstract}
Layout optimization is capable of increasing turbine density and reducing wake effects in wind plants. However, such optimized layouts do not guarantee fixed T-2-T distances in any direction and would be disadvantageous if reduction in computational costs due to turbine set-point updates is also a priority. Regular turbine layouts are considered basic because turbine coordinates can be determined intuitively without the application of any optimization algorithms. However, such layouts can be used to intentionally create directions of large T-2-T distances, hence, achieve the gains of standard/non-optimized operations in these directions, while also having close T-2-T distances in other directions from which the gains of optimized operations can be enjoyed. In this study, a regular hexagonal turbine layout is used to deploy turbines within a fixed area dimension, and a turbulence intensity-constrained axial induction-based plant-wide optimization is carried out using particle swarm, artificial bee colony, and differential evolution optimization techniques. Optimized plant power for three close turbine deployments $(4 D, 5 D$, and $6 D)$ are compared to a non-optimized $7 D$ deployment using three mean wind inflows. Results suggest that a plant power increase of up to $37 \%$ is possible with a $4 \mathrm{D}$ deployment, with this increment decreasing as deployment distance increases and as mean wind inflow increases.
\end{abstract}

Keywords: axial induction; wind plant power maximization; turbulence intensity; particle swarm optimization; artificial bee colony; differential evolution; regular layouts; hexagonal layouts

\section{Introduction}

Given the evident global effects of fossil fuels on the atmosphere, renewable energy sources have become even more vital for energy generation due to its wide availability. The Global Wind Energy Council (GWEC) in their 2020 global wind report suggests that the global wind power must triple over the next decade to avert the most devastating effects on climate change and, hence, keep global warming well below $2^{\circ} \mathrm{C}$ [1]. This projection, together with an annual record high of global wind power installations of 93 GW in 2020, notwithstanding the COVID-19 pandemic, suggests an expected sustained rapid growth in global wind power installations for net zero carbon emissions to be achieved by 2050 [1].

Wind plants provide advantages in terms of economies of scale, increasing the amount of power that can be generated from a given area, reducing access constraints to individual turbines, and reducing length of interconnecting cables, thus reducing operation and maintenance costs [2]. These economies of scale, in most cases, enforce close turbine installations in a wind plant and, although this leads to increased power density, cause aerodynamic interactions, known as wakes, between operating turbines and could negatively impact on plant power production [2]. This negative effect results from deficits in wind velocity available at the hub of each turbine due to its interaction with wakes from turbines around 
it. Besides a reduction in the plant power output, these interactions, which could either be a wake-turbine or wake-wake interaction, also increase the turbulence intensity levels inside the wind plant [3]. Consequently, accurate prediction of turbine wake behavior has become crucial to reduce power losses and improve overall plant efficiency [4]. Several experimental, numerical, and analytical studies have provided insight to turbine wake modeling and effects, with both experimental and numerical models offering high-fidelity solutions compared to analytical methods [4]. The simplicity and low computational cost offered with analytical models make them more attractive, however, in the modeling and optimization of wind plants compared to the slow and computationally expensive numerical and experimental models $[5,6]$.

Analytical wake models are further classified into kinematic (e.g., References $[7,8]$ ) and distributed roughness models (e.g., References $[9,10])$. For accurate prediction of power production of a single turbine, and consequently, the optimization of wind plant power production, kinematic models combine the single wake deficits of individual turbines ahead (in the upstream) of the considered turbine using superposition principles.

Regarding the prediction of turbulence intensity levels in a wind plant where the layout is assumed to be regular, the IEC standard 61400-1 edition 3 utilizes the Frandsen model as specified in amendment 1 of the standard. The accuracy of this model has been tested and validated using measured data from the Greater Gabbard offshore wind plant in Reference [11]. From the study, a simplified implementation of the existing Frandsen model (the wake turbulence (WT) model) was assessed for a location less than $10 \mathrm{D}$ away from an upstream turbine causing the turbulence. This simplified WT model demonstrated generally to better predict turbulence intensity (TI) regardless of distance, compared to the existing Frandsen model. Another model for estimation of TI levels is presented in Reference [12] and is based on a normalization of the standard deviations of wind speed fluctuations in the stream-wise direction $\sigma_{w, x}$, at a particular localized height $z$ and lateral position $y$, with the free-stream wind speed $U_{\infty}$ at height $z$,

$$
\frac{\sigma_{w, x}(y, z)}{U_{\infty}(z)}
$$

However, normalization of wind speed fluctuations with the wind speed at turbine hub height $z_{\text {hub }}$ (as presented by the Frandsen model), rather than at each localized height $z$ is a more frequently employed option [12].

Generally, wind plant layouts utilized in literature largely depend on the wind resource of the site under study. The optimization studies carried out in References [13-15] has demonstrated the wind plant optimization problem to be a multi-dimensional problem. Hence, wind plant layouts could be constrained by several other factors, including electrical cabling costs, plant planning and permissions governing the site, and ease of accessibility, operation, and maintenance, as well as the much known wake losses and fatigue loads. Stated more broadly, layouts found in literature include single-row, regular, and irregular/optimized layouts, with each offering its advantages and disadvantages depending on the scenario considered or wind plant planner's priorities. Regular turbine positioning is considered traditional and limiting [5], but, depending on the configuration chosen and the plant design priority, they could offer significant gains. A regular hexagonal positioning of turbines is more viable for multi-directional sites if improvement in power density, effective management of $\mathrm{TI}$, and reduction in computational costs due to turbine set-point optimization is the priority [16].

Three main ideas exist in literature to optimize the power production of an array of turbines. Firstly, this could be achieved by affecting each turbine's axial induction factor $a$ through coordinated control during the wind plant operation stage to obtain overall plant power increment [17-19]. The aim here is plant level optimality, so turbine-level axial induction factor (control variable) must not necessarily be at optimum for each wind speed and direction. However, plant-level coordinated control must ensure that turbine-level operating limits are not exceeded. Secondly, and more currently, References [14,15] demon- 
strated that improved plant power production can also be achieved through wake-steering during the operation stage. By tuning the yaw angle, wakes from upstream turbines are re-directed away from the nearest downstream turbine, such that the deficits in the wake would have recovered at a further distance where/if it finally hits a downstream turbine positioned even further away in the direction considered. Thirdly, and most commonly, plant power optimization is achieved through plant layout optimization by finding optimal positions for all turbines within the bounded area that reduces the velocity deficits at each turbine; hence, a maximized overall plant power is achieved [14,20]. A combination of wake-steering and layout optimization for plant-level optimization can be seen in References [14,21], with turbine-level control ensured by maintaining an optimal axial induction factor with respect to the mean wind speed at hub height.

Although a very attractive and effective idea, the wake-steering method is an added complexity considering the already complex and multi-dimensional nature of wind plant control. The authors in References [14,15] also admit to not accounting for fatigue loads on the yawing turbines that effect the steering of the wake away from downstream turbines. Hence, in this study, an axial induction-based optimization for plant level power maximization using particle swarm optimization (PSO), artificial bee colony (ABC), and differential evolution (DE) algorithms are presented. The PSO has demonstrated its vastness in the field both for layout optimization [22-24] and for axial induction-based optimization [25-27]. In these aforementioned axial induction-based optimization studies, the authors only optimize for overall power maximization without load considerations which could arise from increasing turbulence intensity levels. The DE in References [28-31] has been employed in the field, but for layout optimization. The ABC, also employed for turbine layout optimization [32], has not been applied for axial induction-based optimization purposes. In this work, however, all three metaheuristic algorithms are applied to optimize the axial induction of each turbine to improve wind plant power, while constraining the turbulence intensity levels at each turbine below a set maximum.

Hence, the objective of the study is to investigate the performance of the PSO, ABC and DE algorithms when applied for TI-constrained axial induction-based wind plant power maximization, in hexagonally deployed wind farms. Furthermore, it explores the potential of power density increment through a combination of turbine density increments and TI-constrained axial induction-based wind plant power maximization.

\section{Materials and Methods}

The methodology developed for this study incorporates an existing wake and turbulence model. In the chosen wake model, the superposition principle applied is guided by the turbine-to-turbine (T-2-T) distances between turbines in the wind plant. The study focuses on optimizing the overall plant power for a wind plant within a fixed area where turbines are deployed following a regular hexagonal. The aim is to improve plant power production by increasing turbine density while ensuring that the resulting increase in TI does not exceed $20 \%$ for wind inflow and direction considered. $4 D, 5 D$, and $6 D$ T-2-T separation distances are studied, and their optimized plant power production is compared to a $7 D$ spacing with no optimization. It is assumed in this study that, at a 7D minimum T-2-T separation distance, wakes from an upstream turbine would have sufficiently recovered, resulting in a negligible velocity deficit at a downstream turbine. Based on observations from Reference [33], such T-2-T separation is a common practice. As such, optimization is deemed unnecessary, to save computational costs. By $n D$, the study implies that the sides of the hexagonal cells, on whose vertices and center turbines are deployed, are $n$ rotor diameters in length.

The system model development is carried out on version 3.9 of the python programming environment. For optimization, the DE model available with the scipy.optimize package in python 3.9 is used, and the PSO algorithm is obtained from Reference [34]. This study implements an adjusted version of the ABC implementation available in Reference [35] by (1) randomly selecting a single variable to be modified from each food 
source in the employee bee stage, instead of modifying all the variables and (2) applying bounds to the selected variable as opposed to not bounding. This ensures generated results are feasible.

\subsection{Power Modeling}

To estimate the power production of a hypothetical wind plant, the power at a given turbine can be computed according to the modeling given in Reference [36]. Wind plant power optimization is then obtained through a coordinated control of all turbines. Hence, the power of a controlled wind turbine can be expressed in Equation (2) based on [36]:

$$
P(U)=\left\{\begin{array}{ll}
0, & \text { if } U<U_{i n} \\
\frac{1}{2} \rho A U^{3} C_{p}, & \text { if } U_{i n} \leq U<U_{r} \\
\frac{1}{2} \rho A U^{3} C_{p}{ }^{*}, & \text { if } U_{r} \leq U<U_{o u t} \\
0, & \text { if } U_{o u t} \leq U .
\end{array} .\right.
$$

where $C_{p}$ and $C_{p}{ }^{*}$ are the design and optimized power coefficients, respectively, and are expressed in Equations (3) and (4). Furthermore, $U_{i n}, U_{r}$, and $U_{o u t}$ are the cut-in, rated, and cut-out wind speeds, respectively.

$$
\begin{gathered}
C_{p}=4 a(1-a)^{2}, \\
C_{p}{ }^{*}=4 a^{*}\left(1-a^{*}\right)^{2},
\end{gathered}
$$

where $a$ is the design axial induction factor of the turbine as specified by the manufacturer. All operating wind speeds have corresponding $C_{p}$ and $a$ values, taking into consideration possible losses in the mechanical and electrical system. Ideally, maximum possible $a$ $\left(a^{\text {max }}\right.$, which is obtainable at $C_{p}{ }^{\text {max }}$ ) $=1 / 3$, according to Betz [37] and can be obtained using Equation (3). The term $a^{*}$ is the optimized axial induction factor-necessary to maintain power at the rated capacity of the turbine when wind inflow exceeds $U_{r}$ or when a plant-wide power optimization is necessary at any operating wind speed below $U_{r}$. The parameter $\rho$ is the air density (considered constant at $1.2253 \mathrm{~kg} / \mathrm{m}^{3}$ ), $A$ is the turbine rotor swept area, and $U$ is the mean wind speed at turbine hub height.

\subsection{Single Wake Model and Superposition Principles for Multiple Wakes}

Where a turbine is under the wakes of more than one upstream turbine, the deficits from all upstream turbines are combined using superposition principles. Four commonly used superposition methods appear in literature [38,39], as summarized in Table 1. Two considerations differentiate these methods: (1) how the single wake velocity deficit $\Delta U_{i}$ induced by an upstream turbine $i$ is defined and (2) how the deficits from all upstream turbines are combined [3].

Table 1. Wake Superposition methods for computing the mean wind velocity due to multiple wakes.

\begin{tabular}{lcc}
\hline Wake Superposition Method & Superposition Principle & Single Wake \\
\hline Ambient-based Linear Sum [8] & $U_{j}=U_{\infty}\left(1-\sum_{i=1}^{\mathcal{T}} \Delta U_{i}\right)$ & $\Delta U_{i}=1-\frac{U_{j}}{U_{\infty}}$ \\
Rotor-based Linear Sum [4] & $U_{j}=U_{\infty}\left(1-\sum_{i=1}^{\mathcal{T}} \Delta U_{i}\right)$ & $\Delta U_{i}=1-\frac{U_{j}}{U_{i^{\prime}}}$ \\
Ambient-based Root Sum Square [7] & $U_{j}=U_{\infty}\left(1-\sqrt{\sum_{i=1}^{\mathcal{T}} \Delta U_{i}^{2}}\right)$ & $\Delta U_{i}=1-\frac{U_{j}}{U_{\infty}}$ \\
Rotor-based Root Sum Square [40] & $U_{j}=U_{\infty}\left(1-\sqrt{\sum_{i=1}^{\mathcal{T}} \Delta U_{i}^{2}}\right)$ & $\Delta U_{i}=1-\frac{U_{j}}{U_{i^{\prime}}}$ \\
\hline
\end{tabular}


From Table $1, U_{j}$ is the resulting mean wake velocity at affected turbine $j, U_{\infty}$ is the mean free-stream velocity entering the wind plant from the direction considered, $\mathcal{T}$ is a set of turbines in the upstream of the affected turbine, and $U_{i^{\prime}}$ is mean wake velocity at the nearest upstream turbine in the direction considered.

To define a single turbine's wake, the study employs a continuous single wake model derived by Reference [41], an extension to the well-known Park model [7], to ensure a smooth variation of wind velocity at the boundary of the cone-shaped wake zone. The model defines a single wake using the ambient-based method and combines multiple wakes using the root sum square method. This study, however, re-defines the single wake model as a rotor-based model but retains the root sum square method for combination of multiple wakes. The decision to re-define the single wake deficit model as a rotor-based model is necessitated by the close T-2-T deployments considered in the study. As such, wake interactions between turbines must be taken into account at each upstream turbine. Assuming a uniform flow hits each turbine's rotor plane, the wake velocity at each turbine in the wake zone of an extracting upstream turbine is given in Equation (5) as:

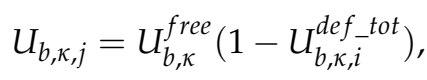

where $U_{b, \kappa}^{\text {free }} \equiv U_{\infty}$ and $U_{b, \kappa, i}^{d e f_{-} t o t}$ is the total velocity deficits suffered due to wakes from the upstream turbines, dependent on the affected turbine $j$, time instance $\kappa$, and wind direction $b$, as given in Equation (6).

$$
U_{b, \kappa, i}^{\text {def } t o t}=\sqrt{\sum_{i=1}^{\mathcal{T}}\left[\frac{2 a_{b, \kappa, i}}{\left(1+\left(\frac{2 \alpha x_{b, \kappa, i}}{D_{i}}\right)\right)^{2}} \exp \left(-\left(\frac{r_{b, \kappa, i}}{\frac{D_{i}}{2}+\alpha x_{b, \kappa, i}}\right)\right)\right]^{2}} .
$$

From Equation (6), the term enclosed in brackets represents a single wake velocity deficit $\Delta U_{i}$ according to Table 1 , and $a_{i}$ and $D_{i}$ denote the upstream turbine(s) axial induction factor(s) and rotor diameter(s), respectively. The parameter $\alpha$ is the decay constant which determines how fast the wake spreads and can be expressed in terms of the roughness length $z_{r_{-} l}$ of the wind plant site and the considered turbine's hub height $z_{0}$, as given in Equation (7). The distance parameters $x$ and $r$ (both in meters) represent the distance of turbine $j$ from each upstream turbine $i \in \mathcal{T}$ in the longitudinal and perpendicular directions, respectively. It is worth noting that $a_{i}$ for each $\Delta U_{i}$ will be computed w.r.t $U_{i^{\prime}}$ as the rotor-based method suggests, and not w.r.t $U_{\infty}$, as proposed by the ambient-based method. The divergence of the wake is then estimated from Equation (8):

$$
\begin{gathered}
\alpha=\frac{0.5}{\ln \frac{z_{0}}{z_{r_{-}}}}, \\
\gamma=2 \tan ^{-1}(\alpha) .
\end{gathered}
$$

\subsection{Turbulence Intensity Model}

This study utilizes the TI model presented in Reference [11], as given in Equation (9), because of the close T-2-T deployment. It is assumed that the wake-generated turbulence presented by Frandsen's simplified WT model is dominant at such close separation distances, encompassing the effects of any ambient turbulence.

$$
T I_{j}=\frac{\sigma_{0, w a k e}}{U_{j}},
$$


with the representative standard deviation $\sigma_{0, w a k e}$ defined in Equation (10) as:

$$
\sigma_{0, w a k e}=\sqrt{\frac{U_{j}^{2}}{\left(1.5+0.8\left(\frac{x^{\text {norm }}}{\sqrt{C_{j}^{\text {thrust }}}}\right)\right)^{2}}}+\sigma_{\text {mean }, 0}^{2}
$$

where $x^{\text {norm }}$ is the longitudinal distance between the nearest upstream turbine $i^{\prime}$ and turbine $j$ normalized with the rotor diameter $D_{j}$, and $\sigma_{\text {mean }, 0}$ is the time-averaged value of standard deviations in wind speed fluctuations within 10-minute periods, for the wind site (0.69). The parameter $C_{j}^{\text {thrust }}$ is the thrust coefficient of turbine $j$ corresponding to $U_{j}$ (wind speed at its hub height), as opposed to $U_{\infty}$ proposed by the Frandsen model (to prevent conservative TI prediction), considering the close T-2-T deployments studied. Table 2 summarizes all parameters used so far in the study.

Table 2. A summary of model parameters and assumptions.

\begin{tabular}{cccc}
\hline Parameter & Meaning & Unit & Value(s) \\
\hline$\rho$ & Atmospheric air density & $\mathrm{kg} / \mathrm{m}^{3}$ & 1.225 \\
$U_{\infty}$ & Mean free-stream wind velocity & $\mathrm{m} / \mathrm{s}$ & $7,8,10$ \\
$U_{b, \kappa, i}^{d e f_{-} t \text { t }}$ & Total velocity deficit at a downstream turbine & $\mathrm{m} / \mathrm{s}$ & variable \\
$U_{i^{\prime}}$ & Mean wake velocity at nearest upstream turbine & $\mathrm{m} / \mathrm{s}$ & variable \\
$U_{j}$ & Mean wake velocity at affected turbine & $\mathrm{m} / \mathrm{s}$ & variable \\
$\Delta U_{i}$ & Wake velocity deficit & $\mathrm{m} / \mathrm{s}$ & variable \\
$\alpha$ & Wake decay constant & - & $\approx 0.083$ \\
$z_{r_{-} l}$ & Surface roughness length & $\mathrm{m}$ & 0.075 \\
$z_{0}$ & Turbine hub height & $\mathrm{m}$ & - \\
$\sigma_{\text {mean, }}$ & Mean of STDs in wind speed fluctuations & & $\approx 0.691$ \\
\hline
\end{tabular}

\subsection{Wind Plant Layout, Turbine Characteristics}

In this study, a hypothetical wind plant site of fixed area $698 \times 1128 \mathrm{~m}^{2}$, in which turbines can be placed with a minimum spacing of $4 D$, is considered. A regular hexagonal deployment is employed to maximize turbine density, with Figure 1 depicting this arrangement for a $7 D$ deployment (hexagonal side $=7 D$ ). For all T-2-T distances studied, distances $E=F=G$, and $K=L$, and their values are specified in Table 3. This deployment strategy is not uncommon as it is the original configuration of the Princess Amalia wind plant (PAWP), an offshore wind plant in the North Sea comprising 60 turbines and located $23 \mathrm{~km}$ off the coast of the Netherlands. The PAWP, as shown in Figure 2, has been extensively studied in the literature [14,15], with the aim to maximize its overall plant power through layout optimization and yaw control. The power and thrust curve of the studied turbine is presented in Figure 3. A $z_{r_{-} l}$ value of $0.075 \mathrm{~m}$ is used as recommended for most land cases, by Reference [42]. On Table 4, an abridged version of the turbine axial induction data is given.

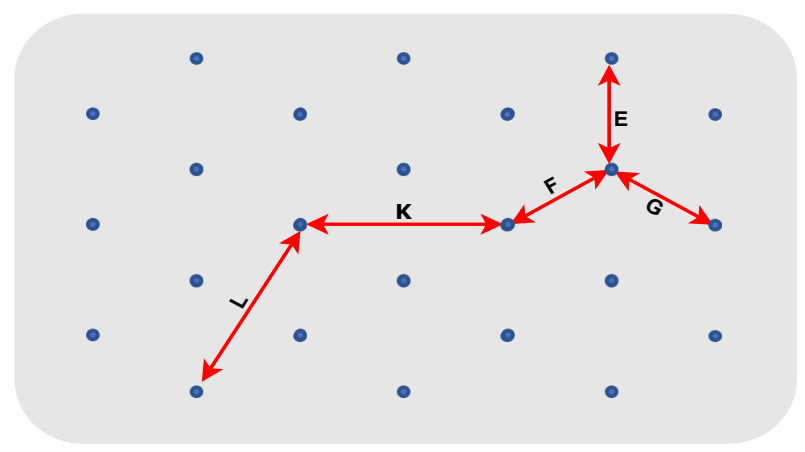

Figure 1. A regular hexagonal layout of turbines with hexagonal side $=7 D$. 
Table 3. Turbine to turbine (T-2-T) separation distances in rotor diameters.

\begin{tabular}{ccc}
\hline Minimum T-2-T Distance $(D)$ & $E=F=G$ & $K=L$ \\
\hline 7 & 7 & $\approx 12.12$ \\
6 & 6 & $\approx 10.4$ \\
5 & 5 & $\approx 8.66$ \\
4 & 4 & $\approx 6.92$ \\
\hline
\end{tabular}

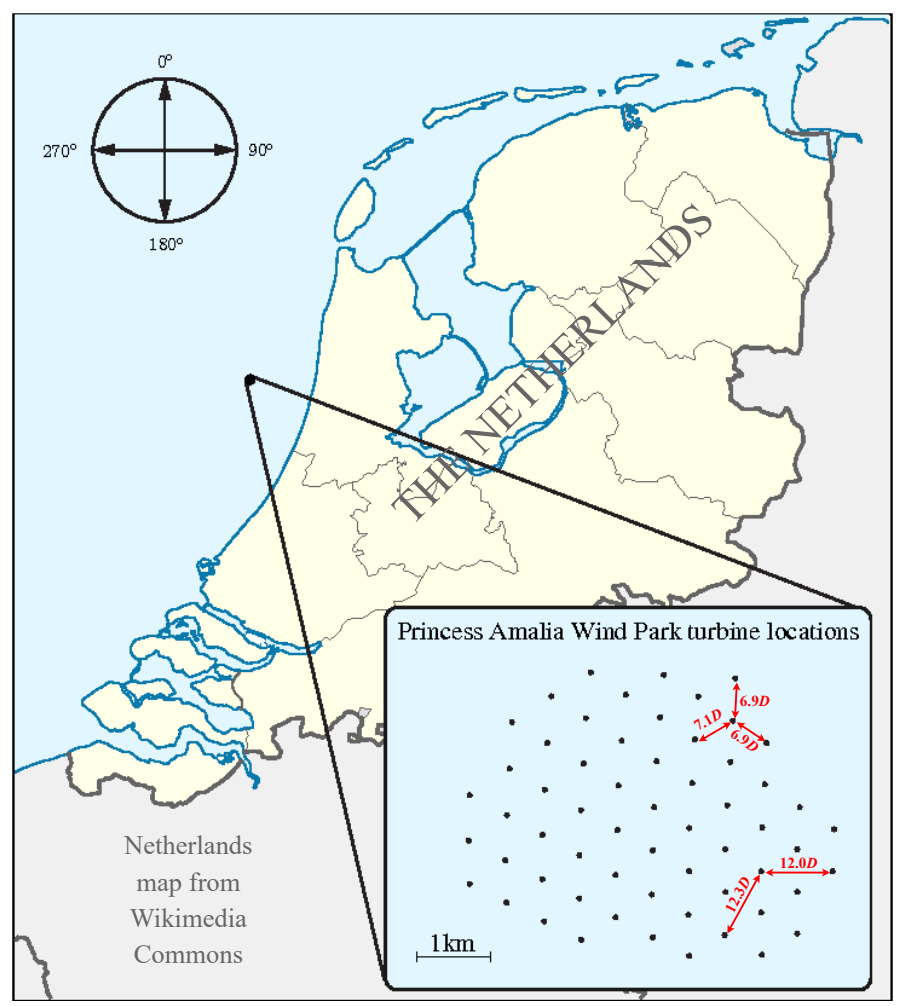

Figure 2. The Princess Amalia wind plant showing a regular hexagonal turbine layout [43].

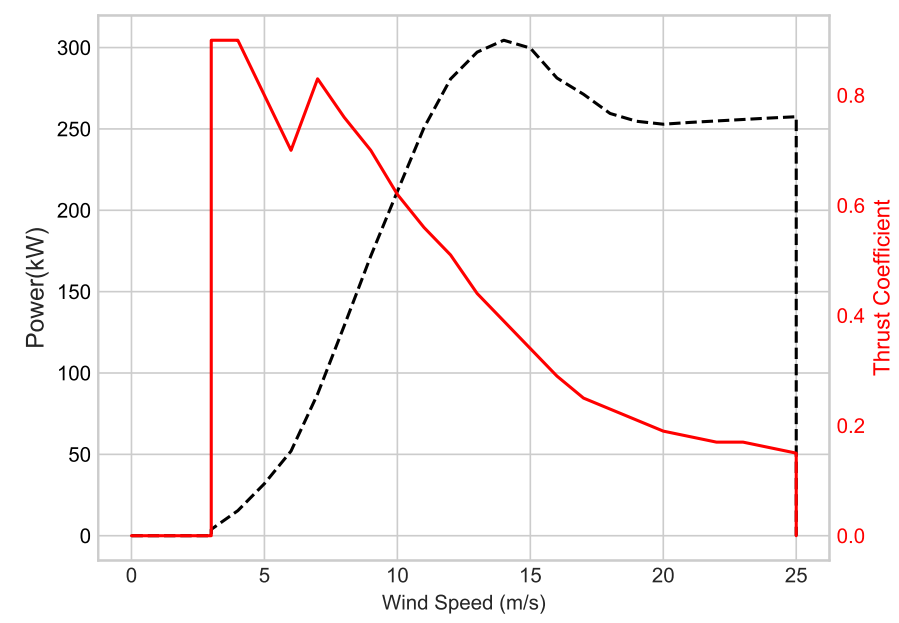

Figure 3. Turbine Power and Thrust Curve: Power $(\mathrm{kW})$ and thrust coefficient $\left(C_{t}\right)$ versus wind speed $(\mathrm{m} / \mathrm{s})$ of the Bonus $300 \mathrm{~kW}$ MkIII wind turbine generator with $U_{\text {in }}=3 \mathrm{~m} / \mathrm{s}, U_{r}=14 \mathrm{~m} / \mathrm{s}$, $U_{\text {out }}=25 \mathrm{~m} / \mathrm{s}, D=31 \mathrm{~m}$, and $z_{\text {hub }}=30 \mathrm{~m}, C_{p}{ }^{\max }=0.5923$ [44]. 
Table 4. Turbine axial data $\left(U_{\text {in }}\right.$ to $\left.U_{r}\right)$.

\begin{tabular}{lcccccc}
\hline$U(\mathbf{m} / \mathbf{s})$ & $\mathbf{3}$ & $\mathbf{4}$ & $\mathbf{5}$ & $\mathbf{6}$ & $\mathbf{7}$ & $\mathbf{8}$ \\
\hline$a$ & 0.3418861 & 0.3418861 & 0.2763932 & 0.2261387 & 0.2938447 & 0.25505103 \\
\hline$U(\mathbf{m} / \mathbf{s})$ & $\mathbf{9}$ & $\mathbf{1 0}$ & $\mathbf{1 1}$ & $\mathbf{1 2}$ & $\mathbf{1 3}$ & $\mathbf{1 4}$ \\
\hline$a$ & 0.2261387 & 0.1917793 & 0.1683375 & 0.15 & 0.1258342 & 0.10948752 \\
\hline
\end{tabular}

\section{Wind Plant Optimization and Control}

In this section, a coordinated control of wind turbines in a wind plant using $\mathrm{ABC}, \mathrm{DE}$, and PSO algorithms is presented. All three algorithms are metaheuristics and have shown good global search capabilities according to literature [23]. Consequently, all three schemes have been applied to all the deployment distances to find optimal set-points for each turbine in a major wake zone (MWZ) that yields an improved total plant power production when compared to a counterpart base case where there is no optimization. Since the main aim is to improve power density, the methods are also applied to obtain an optimal plant power for the $4 D, 5 D$, and $6 D$ deployments that surpass that of the non-optimized $7 D$ deployment (the benchmark), while keeping TI levels below a recommended $20 \%$ (TI ${ }^{\max }$ ).

Suppose that wind is blowing into a bounded hypothetical wind plant, as shown in Figure 4. Consider that $\mathcal{N}$ is a set of all turbines in the wind plant, $\mathcal{M} \subseteq \mathcal{N}$ is a set of MWZs, $m$, and $\mathcal{T}$ is a set of turbines in $m$. In addition, let $\mathcal{L}$ be a set comprising all the furthermost turbines in each $m$. Considering Figure 4 , and for ease of understanding and simplicity, each $m$ is identified by the number of the uppermost upstream turbine w.r.t the direction of wind inflow. Given that the area of the plant is fixed, values of $\mathcal{M}$ and $\mathcal{N}$ decrease as minimum deployment distance increases, as shown in Table 5.

Table 5. Table showing different deployments and their set components.

\begin{tabular}{|c|c|c|c|c|c|c|c|c|c|c|c|}
\hline \multicolumn{12}{|c|}{$4 D \quad(\mathcal{N}=66)$} \\
\hline$m$ & 5 & 11 & 17 & 23 & 29 & 35 & 41 & 47 & 53 & 59 & 65 \\
\hline $\mathcal{T}(i)$ & $\begin{array}{c}\{5, \ldots, \\
0\}\end{array}$ & $\begin{array}{c}\{11, \ldots, \\
6\}\end{array}$ & $\begin{array}{c}\{17, \ldots, \\
12\}\end{array}$ & $\begin{array}{c}\{23, \ldots \\
18\}\end{array}$ & $\begin{array}{c}\{29, \ldots, \\
24\}\end{array}$ & $\begin{array}{c}\{35, \ldots, \\
30\}\end{array}$ & $\begin{array}{l}\{41, \ldots, \\
36\}\end{array}$ & $\begin{array}{c}\{47, \ldots, \\
42\}\end{array}$ & $\begin{array}{c}\{53, \ldots, \\
48\}\end{array}$ & $\begin{array}{c}\{59, \ldots, \\
54\}\end{array}$ & $\begin{array}{r}\{65, . . \\
60\}\end{array}$ \\
\hline$\overline{\mathcal{T}}$ & 6 & 6 & 6 & 6 & 6 & 6 & 6 & 6 & 6 & 6 & 6 \\
\hline$i \in L$ & 0 & 6 & 12 & 18 & 24 & 30 & 36 & 42 & 48 & 54 & 60 \\
\hline \multicolumn{12}{|c|}{$5 D \quad(\mathcal{N}=45)$} \\
\hline$m$ & 4 & 9 & 14 & 19 & 24 & 29 & 34 & 39 & 44 & - & - \\
\hline $\mathcal{T}(i)$ & $\begin{array}{c}\{4, \ldots, \\
0\}\end{array}$ & $\begin{array}{c}\{9, \ldots, \\
5\}\end{array}$ & $\begin{array}{c}\{14, \ldots, \\
10\}\end{array}$ & $\begin{array}{c}\{19, \ldots, \\
15\}\end{array}$ & $\begin{array}{c}\{24, \ldots, \\
20\}\end{array}$ & $\begin{array}{c}\{25, \ldots, \\
29\}\end{array}$ & $\begin{array}{l}\{30, \ldots, \\
34\}\end{array}$ & $\begin{array}{c}\{35, \ldots, \\
39\}\end{array}$ & $\begin{array}{c}\{40, \ldots, \\
44\}\end{array}$ & - & - \\
\hline $\mathcal{T}$ & 5 & 5 & 5 & 5 & 5 & 5 & 5 & 5 & 5 & - & - \\
\hline$\overline{i \in L}$ & 0 & 5 & 10 & 15 & 20 & 25 & 30 & 35 & 40 & - & - \\
\hline \multicolumn{12}{|c|}{$6 D \quad(\mathcal{N}=32)$} \\
\hline$m$ & 1 & 2 & 3 & 4 & 5 & 13 & 21 & 35 & - & - & - \\
\hline $\mathcal{T}(i)$ & $\begin{array}{c}\{3, \ldots, \\
0\}\end{array}$ & $\begin{array}{c}\{7, \ldots, \\
4\}\end{array}$ & $\begin{array}{c}\{11, \ldots, \\
8\}\end{array}$ & $\begin{array}{c}\{15, \ldots, \\
12\}\end{array}$ & $\begin{array}{c}\{19, \ldots, \\
16\}\end{array}$ & $\begin{array}{c}\{23, \ldots, \\
20\}\end{array}$ & $\begin{array}{l}\{27, \ldots, \\
24\}\end{array}$ & $\begin{array}{c}\{31, \ldots, \\
28\}\end{array}$ & - & - & $\begin{array}{l}- \\
-\end{array}$ \\
\hline $\mathcal{T}$ & 4 & 4 & 4 & 4 & 4 & 4 & 4 & 4 & - & - & - \\
\hline$i \in L$ & 0 & 4 & 8 & 12 & 16 & 20 & 24 & 28 & - & - & - \\
\hline \multicolumn{12}{|c|}{$7 D \quad(\mathcal{N}=24)$} \\
\hline$m$ & 3 & 7 & 11 & 14 & 17 & 20 & 23 & - & - & - & - \\
\hline $\mathcal{T}(i)$ & $\begin{array}{c}\{3, \ldots, \\
0\}\end{array}$ & $\begin{array}{c}\{7, \ldots, \\
4\}\end{array}$ & $\begin{array}{c}\{11, \ldots, \\
8\}\end{array}$ & $\begin{array}{c}\{14, \ldots \\
12\}\end{array}$ & $\begin{array}{c}\{17, \ldots, \\
15\}\end{array}$ & $\begin{array}{c}\{20, \ldots, \\
18\}\end{array}$ & $\begin{array}{l}\{23, \ldots, \\
21\}\end{array}$ & - & - & - & - \\
\hline $\mathcal{T}$ & 4 & 4 & 4 & 3 & 3 & 3 & 3 & - & - & - & - \\
\hline$i \in L$ & 0 & 4 & 8 & 12 & 15 & 18 & 21 & - & - & - & - \\
\hline
\end{tabular}




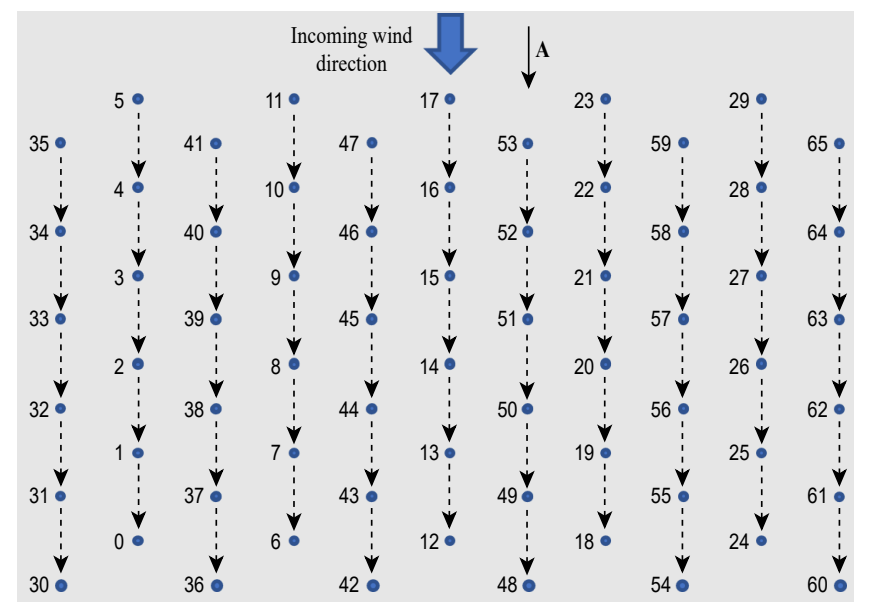

Figure 4. A regular hexagonal layout with hexagonal side of $4 D$, showing direction of inflow.

Consider a major wake zone $m$ of $\mathcal{T}$ turbines with power productions $\left\{P_{i}\right\}_{i \in \mathcal{T}}$ and control settings $\left\{a_{i}\right\}_{i \in \mathcal{T}}$ that are standing in the wake of each other, with a free-stream inflow $U_{\infty}$ from the direction illustrated on Figure 3. The optimization variable considered in this study for plant power maximization is the axial induction factor $a$; hence, an adjustment in $a$ of any $i \in \mathcal{T}$ in $m$ affects turbine $i$ 's power production and those of others in its downstream. Optimal settings of $a \forall i \in \mathcal{T}, \forall m \in \mathcal{M}$, and $\forall b \in \mathcal{B}$, thus, will produce a maximized plant power output per instance of time.

The optimization problem can, thus, be formulated as:

$$
\begin{aligned}
\max _{\left(U_{m, i}, P_{m, i}\right)} & \sum_{b=1}^{\mathcal{B}} \sum_{m=1}^{\mathcal{M}} \sum_{i=1}^{\mathcal{T}} \beta_{b, m, i} U_{b, m, i}^{3} \quad \forall i \in \mathcal{M} \\
\text { s.t. } \quad & a_{m, i} \leq a^{\text {max }} \\
& 0<\beta_{b, m, i} U_{b, m, i}^{3} \leq P^{\text {max }} \\
& T I \leq T I^{\text {max }} \\
& \sum_{i=1}^{\mathcal{T}} \beta_{m, i}^{\text {ideal }} U_{m, i}^{3}<\sum_{i=1}^{\mathcal{T}} \beta_{b, m, i}^{*} U_{b, m, i}^{3}
\end{aligned}
$$

where $U$ is expressed in Equation (5), and $\beta$ is given in Equations (12) and (13) in its non-optimized and curtailed (optimized) forms, respectively.

$$
\begin{aligned}
& \beta_{b, m, i}=\frac{\rho A C_{p_{b, m, i}}}{2}, \\
& \beta_{b, m, i}^{*}=\frac{\rho A C_{p_{b, m, i}}{ }^{*}}{2},
\end{aligned}
$$

with $C_{p_{b, m, i}}$ representing the design power coefficient (due to non-optimized axial induction and wakes), and $C_{p_{b, m, i}}{ }^{*}$ representing the optimized power coefficients (due to optimized axial induction and wakes). The maximum power that can be generated by a turbine based on the free-stream wind inflow $P^{\max }$ is then given in Equation (14) as:

$$
P^{\max }=P^{\text {free }}=\beta_{b, m, i} U_{\infty}^{3} .
$$

Constraint 1 prevents the axial induction factor of each turbine from exceeding the manufacturer's maximum design power coefficient (obtainable at $U_{i n}$ for the turbine model studied). This constrains the value of $C_{p}{ }^{*}$ in Equation (13). Constraint 2 ensures no turbine power exceeds that which it would generate at the mean free-stream inflow $U_{\infty}$ and at the design axial induction factor synonymous with that free-stream inflow, while also making sure that all turbines generate power. Constraint 3 limits TI from exceeding 
recommendation, and constraint 4 seeks to ensure that optimized MWZ power exceeds that of the base case.

The efficiency of the optimized cases and the benchmark is computed using Equation (15).

$$
\text { Efficiency }=\frac{P^{\text {total }}}{P^{w f}}
$$

where $P^{t o t a l}$ and $P^{w f}$ are defined in Equations (16) and (17) as the total optimized plant power considering wakes and the total non-optimized plant power without wakes.

$$
\begin{gathered}
P_{m, i}^{\text {total }}=\sum_{b=1}^{\mathcal{B}} \sum_{m=1}^{\mathcal{M}} \sum_{i=1}^{\mathcal{T}} \beta_{b, m, i}^{*} U_{b, m, i}^{3}, \\
P^{w f}=\mathcal{N} *\left(\beta^{\infty} U_{\infty}^{3}\right),
\end{gathered}
$$

where $\beta^{\infty}$ is the non-optimized no-wake version of $\beta$. The term $\beta_{b, m, i}^{*}$ in Equation (16) is applied for the optimized cases, but it is replaced with $\beta_{b, m, i}$ for the benchmark.

Algorithm 1 describes the operation of the wind plant optimization. Using the parameters presented in Table 6, 1000 iteration runs were carried out for each algorithm using the following algorithm-specific parameters-PSO (Particles $=30, c 1=2, c 2=2, w$ Max $=0.9$, $w$ Min $=0.2)$; DE (strategy $=$ 'best1bin', maxiter $=1000$, popsize $=30$, mutation $=(0.5,1)$, $C R=0.7) ; \mathrm{ABC}($ Employee $=$ Onlookerbees $=30$, limit $=$ populationsize $*$ variablesize $)$, where each deployment has a variable size $\mathcal{N}$.

Table 6. Simulation parameters.

\begin{tabular}{cccc}
\hline Symbol & Meaning & Unit & Value \\
\hline fixed_area & Fixed wind plant area dimension & $\mathrm{m}^{2}$ & $698 \times 1128$ \\
$T I_{\text {max }}$ & Recommended turbulence Intensity & $\%$ & 20 \\
$\mathcal{N}$ & Set of all turbines in wind plant & - & variable \\
$m$ & Major wake zone & - & variable \\
$\mathcal{M}$ & Set of $m$ in wind plant & - & variable \\
$\mathcal{T}$ & Set of turbines in each $m$ & - & variable \\
$\mathcal{B}$ & Set of wind direction bins & - & 1 \\
$i$ & Wind turbine & - & - \\
$\mathcal{K}$ & Time instance & $\mathrm{s}$ & variable \\
$b$ & Wind direction bin & - & 1 \\
$a$ & Axial induction factor of turbine & - & variable \\
$a^{\text {max }}$ & Maximum Axial induction factor & - & $\approx 0.325$ \\
$C_{p}$ max & Power coefficient of turbine & $\mathrm{W}$ & $\approx 0.592$ \\
Pax & Maximum turbine power & $\mathrm{m}$ & variable \\
$D$ & Turbine rotor diameter & - & 31 \\
max_it & Maximum iteration & - \\
\hline
\end{tabular}




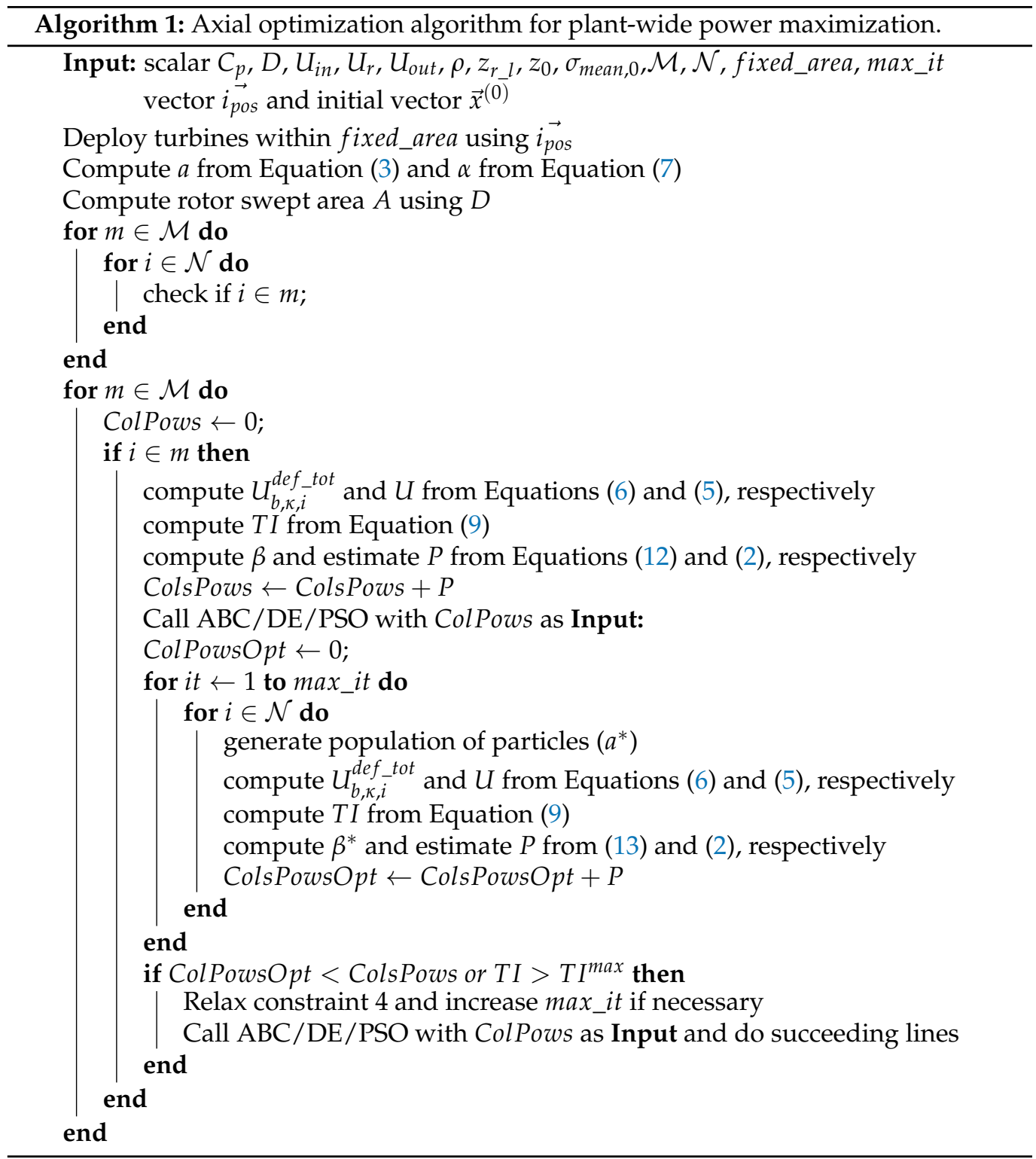

\section{Results}

To observe and analyze the non-optimized and optimized system behavior, results are presented in this section for a single MWZ (since all MWZs in the direction studied contain equal number of turbines with same separation distances) and for all deployment distances studied. Firstly, a convergence plot is given in Figure 5 to capture the convergence for the ABC and PSO algorithms. Both algorithms attained a quick convergence well before max_it. Considering this, it was reasonable to set max_it as the termination criterion. This decision was further validated by the time-consuming and computationally expensive nature of the $\mathrm{ABC}$ algorithm, knowing that any chosen max_it is executed at least twice (first, for the employee bee phase and second, for the onlooker bee phase) and then a possibility of additional iteration counts for the scout bee phase. Considering the limited computational resource at our disposal: a Proline desktop PC with an intel quad-core core i5 processor clocking at $3.2 \mathrm{GHz}$, a 16GB physical RAM, and a $1 \mathrm{~TB}$ disk space, it was reasonable to select a max_it that is not too large, but allows for a complete settling of the objective function over a sufficiently long duration. Note that the convergence plot does not contain the DE algorithm. Based on our observation, the scipy.optimize package tends to override the maxiter value set by the user, using its default termination criterion, thus 
terminating way earlier than the 1000th iteration. As a result, 1000 iterations could not be obtained for the plot. Since optimizations are done per MWZ, the convergence plots are obtained per MWZ, too. Hence, Figures 5 and 6 represent a single MWZ and must be multiplied by the number of MWZs, $m$ in either deployments shown in the figures, to obtain the total plant powers which is presented later in the chapter.

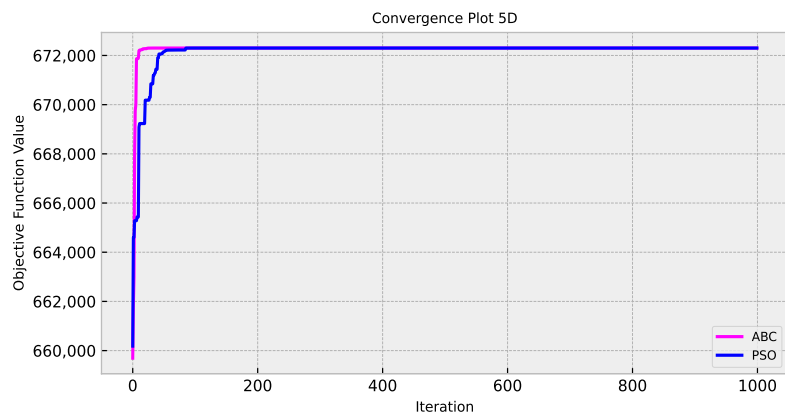

Figure 5. Convergence plot for $5 \mathrm{D}$ at $10 \mathrm{~m} / \mathrm{s}$ mean wind speed.

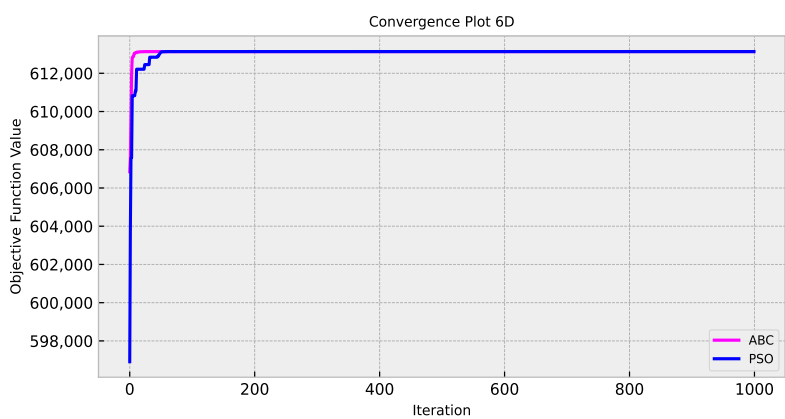

Figure 6. Convergence plot for $6 \mathrm{D}$ at $10 \mathrm{~m} / \mathrm{s}$ mean wind speed.

In each scenario shown in Figures 7-16, the base case is compared to the optimized cases in terms of wind inflow, power production, and TI experienced at each turbine in a MWZ. A single wind direction is studied, as shown in Figure 4, using three mean inflow wind conditions $(7,8$, and $10 \mathrm{~m} / \mathrm{s})$. Wind rose and wind speed distribution for the considered site is given in Appendix A section. No consideration of ambient turbulence is taken into account because of the TI model studied, as described in Section 2.3.

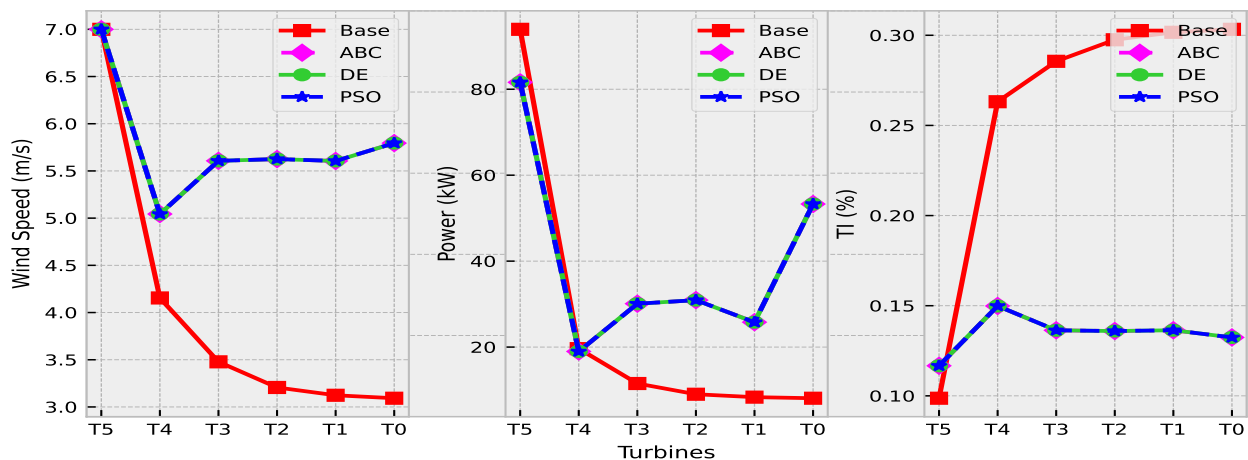

Figure 7. $4 D$ deployment distance at $7 \mathrm{~m} / \mathrm{s}$ mean wind speed. 


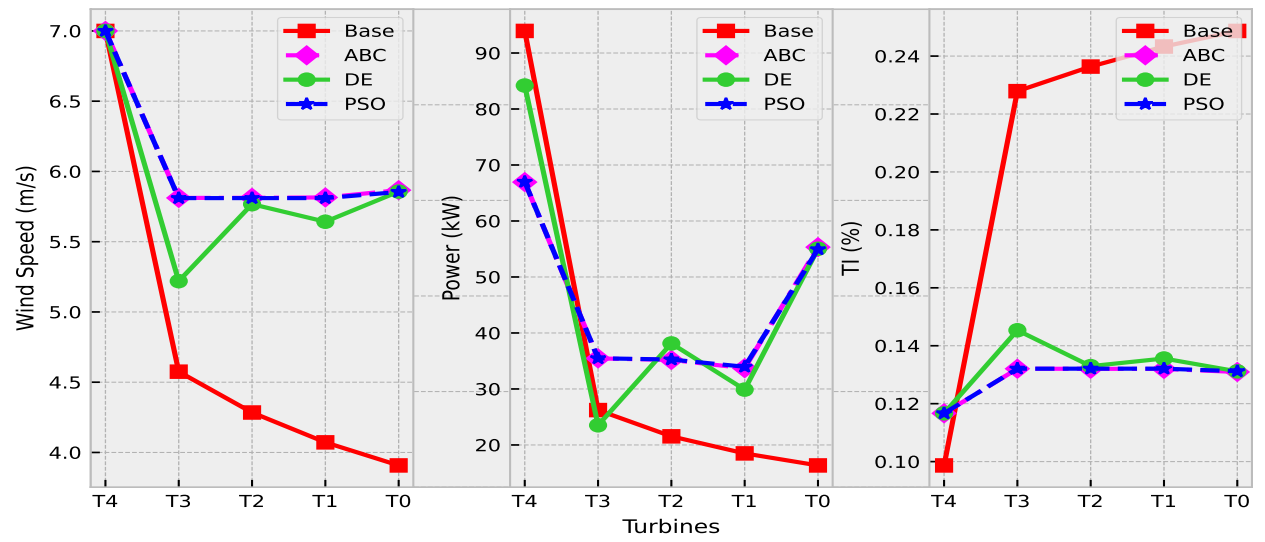

Figure 8. 5D deployment distance at $7 \mathrm{~m} / \mathrm{s}$ mean wind speed.

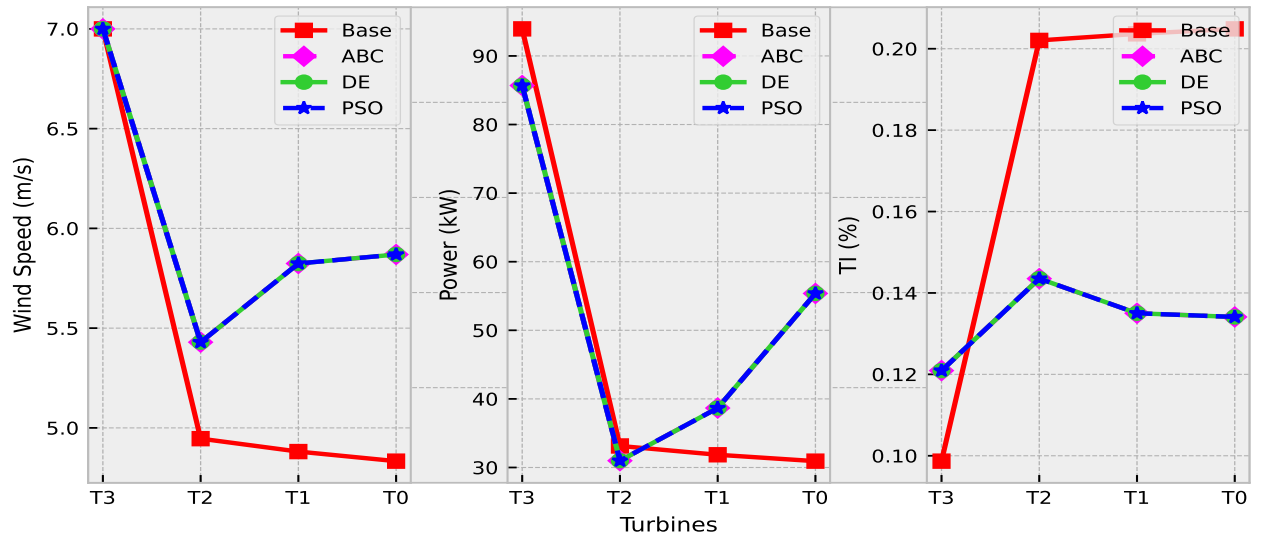

Figure 9. $6 D$ deployment distance at $7 \mathrm{~m} / \mathrm{s}$ mean wind speed.

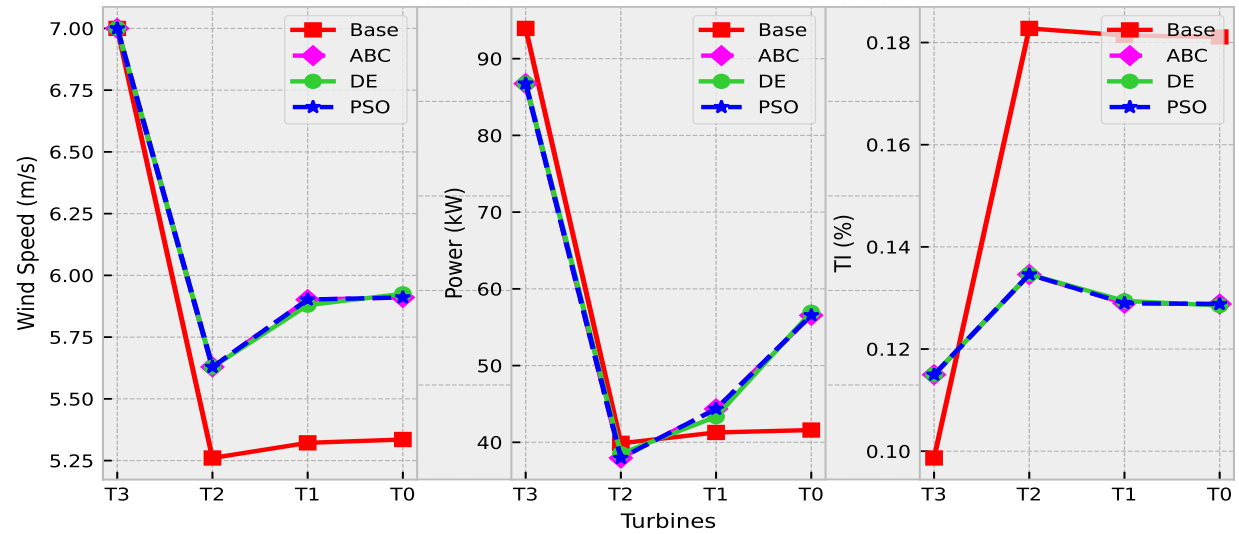

Figure 10. $7 \mathrm{D}$ deployment distance at $7 \mathrm{~m} / \mathrm{s}$ mean wind speed. 


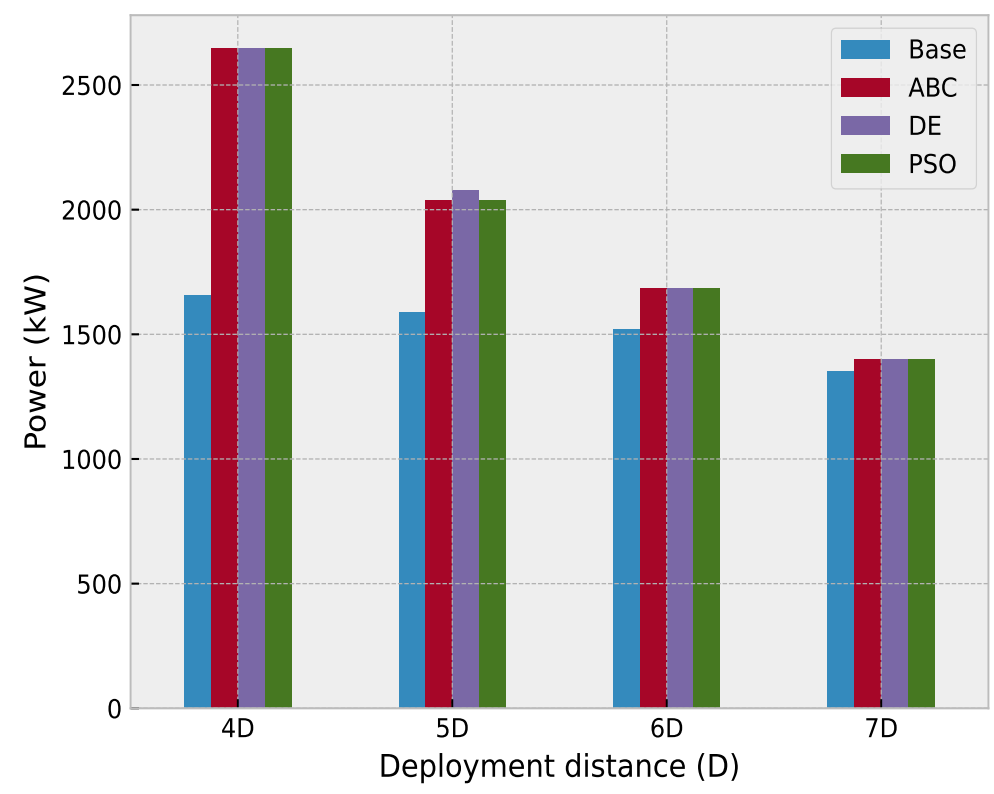

Figure 11. Total plant power for all deployment distances, at $7 \mathrm{~m} / \mathrm{s}$ mean wind speed.

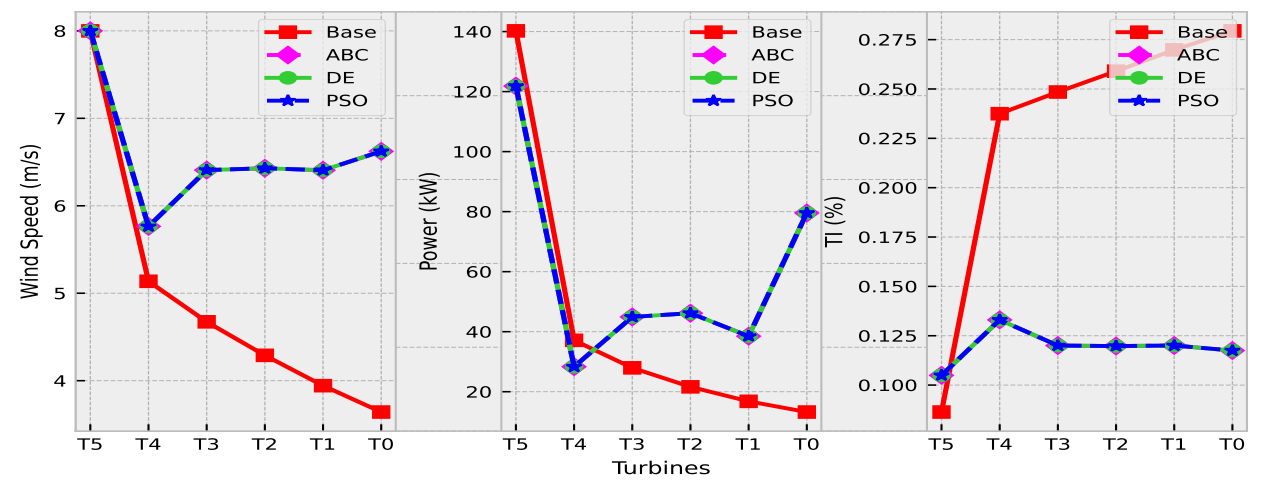

Figure 12. $4 D$ deployment distance at $8 \mathrm{~m} / \mathrm{s}$ mean wind speed.

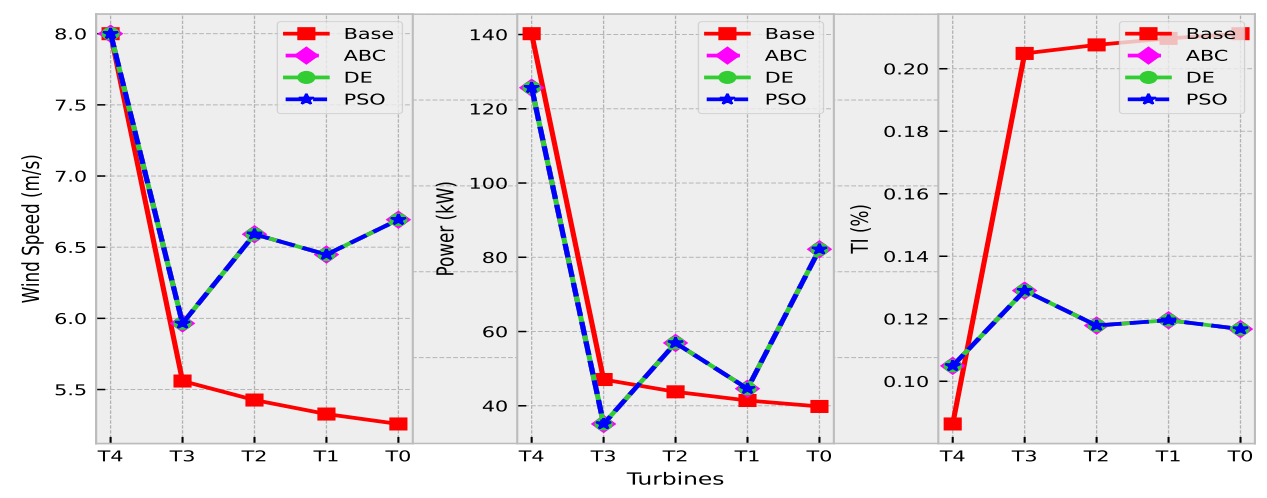

Figure 13. $5 D$ deployment distance at $8 \mathrm{~m} / \mathrm{s}$ mean wind speed. 


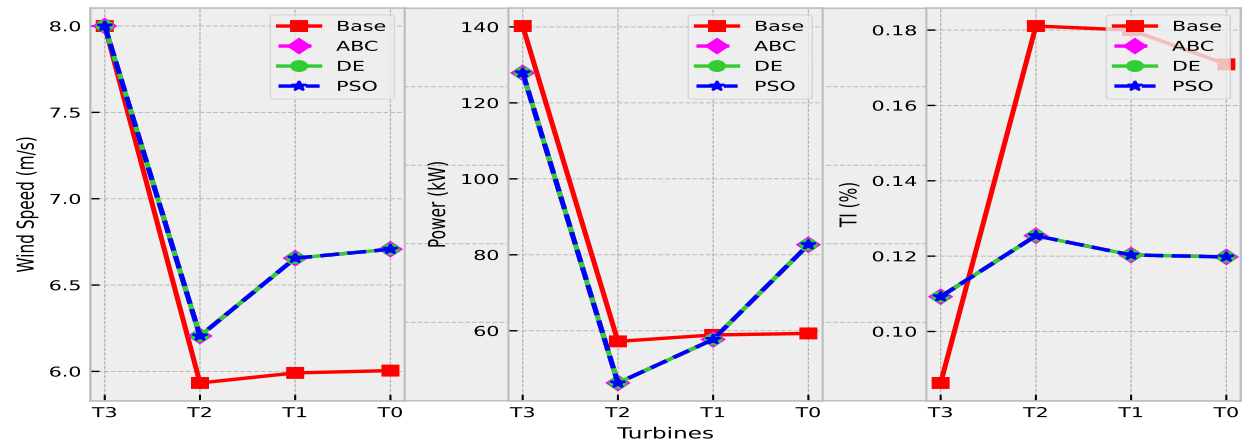

Figure 14. $6 D$ deployment distance at $8 \mathrm{~m} / \mathrm{s}$ mean wind speed.

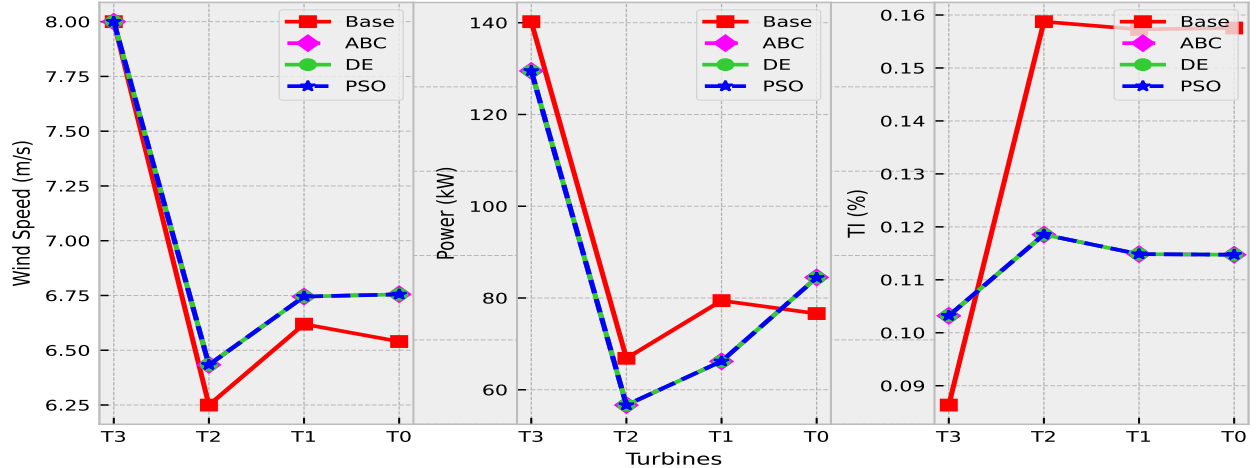

Figure 15. $7 D$ deployment distance at $8 \mathrm{~m} / \mathrm{s}$ mean wind speed.

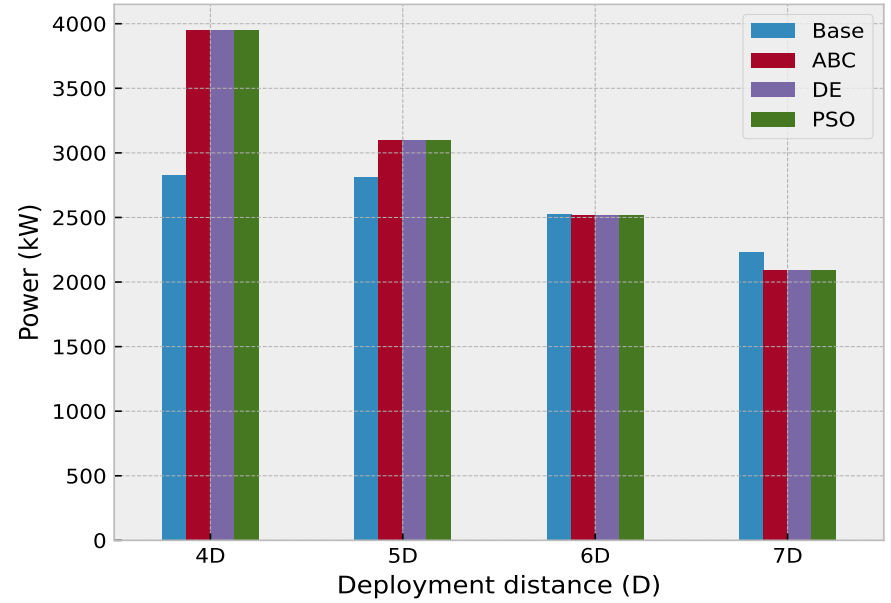

Figure 16. Total plant power for all deployment distances, at $8 \mathrm{~m} / \mathrm{s}$ mean wind speed.

\subsection{Base Case Operation}

The base case operation highlights the normal behavior of the turbines when the studied wake and turbulence models are coupled. The wind speed profile shows a gradual saturation of wake deficits along a MWZ moving from the first turbine to the last, consistent with expectations from Park's model from which the studied model is developed. This is due to the squared effect on each individual upstream turbine deficit on considered downstream turbine [7]. This behavior is experienced across all deployment distances except the 7D deployment and could be attributed to either the re-definition of the single wake model as a rotor-based model or to the turbine model used for the study. 


\subsection{Optimized Operation}

For the $4 D$ deployment, optimizing the axial induction factor of all turbines in the MWZ causes a derating of approximately $13 \%$ by turbine $T 1$ (for all schemes), with all other turbines but $T 2$ experiencing power gains, as seen on Figure 7 . This power reduction by turbine $T 1$ produces an overall MWZ power and, consequently, plant power increment of $37.4 \%$. This is accompanied by a maximum TI of $15 \%$ (across all turbines in MWZ) as given in Table 7 . Given that turbine $T 6$ does not suffer any power reduction as the furthest turbine in the MWZ (since its axial induction factor does not affect any turbine but itself), it experiences the largest power gain. For all deployments, the total MWZ increment corresponds to a total plant power increment because all MWZs in the direction considered contain the same number of turbines, as evident in Figure 4.

As demonstrated in Figure 8, the 5D deployment induces a derating of approximately $29 \%$ (ABC and PSO) and $10.4 \%$ (DE) on $\mathrm{T} 1$. The DE, however, also derates $\mathrm{T} 2$ by $10.3 \%$, resulting in a MWZ and plant power increment of approximately $23.5 \%$, better than the $22 \%$ achieved by the ABC and PSO schemes, as shown in Figure 11.

With the $6 D$ deployment in Figure 9, turbines $T 1$ and $T 2$ experience power reductions of about $9 \%$ and $6.5 \%$, respectively. Consequently, a MWZ and plant power increment of $9.89 \%$ is observed for all schemes.

For a $7 \mathrm{~m} / \mathrm{s}$ inflow, the $7 D$ deployment as expected produces the least MWZ and plant power increment of approximately $3.95 \%$, with $T 1$ and $T 2$ suffering reductions.

Figures 12-16, which follow next, show variations with an $8 \mathrm{~m} / \mathrm{s}$ mean inflow.

With an $8 \mathrm{~m} / \mathrm{s}$ inflow and a $4 D$ deployment, all schemes derate $T 1$ and $T 2$ by approximately $13 \%$ and $23.7 \%$, respectively, leading to a $28.5 \%$ increase in MWZ and overall plant power.

The same pattern is observed in the $5 D$ deployment for this mean inflow. Both $T 1$ and T2 are derated by $10.4 \%$ and $25.4 \%$, respectively, consequently, increasing both MWZ and plant power by approximately $9.3 \%$.

For a $6 D$ deployment distance, applying power reductions to three of the four turbines in the MWZ results in a MWZ and overall plant power decrease of $0.34 \%$

Figure 16 shows that an increase in deployment distance to $7 D$ yields a further decrease in MWZ and overall plant power by 7.25\% compared to the base or non-optimized case.

Given that the $6 D$ and $7 D$ deployments yielded power decrements rather than increments for the $8 \mathrm{~m} / \mathrm{s}$ inflow, the same pattern was expected if the mean inflow is increased. The $10 \mathrm{~m} / \mathrm{s}$ mean inflow, however, as shown in Figure 17 and Table 7, does not follow this pattern as the $6 D$ deployment witnesses a power increment, albeit marginal.

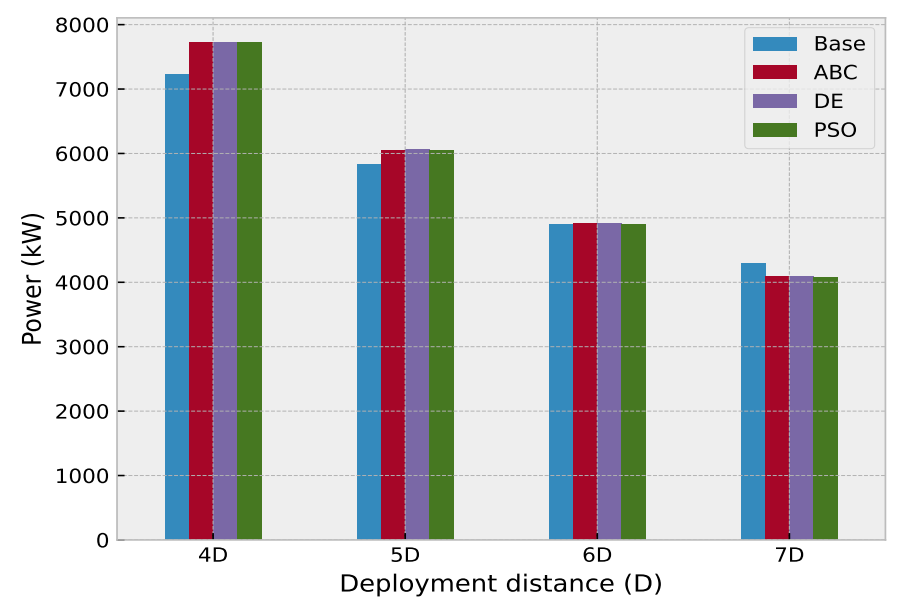

Figure 17. Total plant power for all deployment distances, at $10 \mathrm{~m} / \mathrm{s}$ mean wind speed. 
Table 7 shows how each optimized plant scenario compares to the non-optimized/base case in terms of power increments/decrements and TI levels. Furthermore, a comparison of overall plant power for each deployment distance with the benchmark 7D deployment is summarized in Table 8. Figures 18 and 19 illustrate the variation of wind plant efficiency with the different deployments and with wind speed.

Table 7. MWZ and wind plant power increments with averaged TI decrements in comparison with base case (Base) for all scenarios.

\begin{tabular}{ccccc}
\hline \multirow{2}{*}{ Scenario } & \multicolumn{4}{c}{ Power Change (\%) } \\
\cline { 2 - 5 } & ABC & DE & PSO & Max TI (\%) \\
\hline $7 \mathrm{~m} / \mathrm{s}$ & +37.4 & +37.4 & +37.4 & 14.9 \\
$4 D: 8 \mathrm{~m} / \mathrm{s}$ & +28.5 & +28.5 & +28.5 & 13.3 \\
$10 \mathrm{~m} / \mathrm{s}$ & +6.31 & +6.31 & +6.31 & 11.4 \\
\hline $7 \mathrm{~m} / \mathrm{s}$ & +22.1 & +23.5 & +22.1 & 14.5 \\
$5 D: 8 \mathrm{~m} / \mathrm{s}$ & +9.34 & +9.34 & +9.34 & 12.9 \\
$10 \mathrm{~m} / \mathrm{s}$ & +3.69 & +3.77 & +3.69 & 11.1 \\
\hline $7 \mathrm{~m} / \mathrm{s}$ & +9.90 & +9.90 & +9.90 & 14.4 \\
$6 D: 8 \mathrm{~m} / \mathrm{s}$ & -0.35 & -0.35 & -0.35 & 11.2 \\
$10 \mathrm{~m} / \mathrm{s}$ & +0.20 & +0.25 & +0.05 & 13.5 \\
\hline $7 \mathrm{~m} / \mathrm{s}$ & +3.95 & +3.95 & +3.95 & 11.9 \\
$7 D: 8 \mathrm{~m} / \mathrm{s}$ & -7.24 & -7.25 & -7.25 & 10.3 \\
\hline $10 \mathrm{~m} / \mathrm{s}$ & -3.48 & -3.50 & -3.79 &
\end{tabular}

Table 8. Wind plant power increments in comparison with 7D benchmark (BM).

\begin{tabular}{ccccc}
\hline \multirow{2}{*}{ Deployment and Power (kW) } & \multicolumn{2}{c}{ Non-Optimized BM } & \multicolumn{2}{c}{ Optimized BM } \\
\cline { 2 - 5 } & Power (kW) & Power Change (\%) & Power (kW) & Power Change (\%) \\
\hline $4 D: 2647$ & 1350 & -48.9 & 1401 & -47.1 \\
5D: 2052 & 1350 & -34.1 & 1401 & -31.7 \\
6D: 1685 & 1350 & -19.9 & 1401 & -16.9 \\
\hline
\end{tabular}

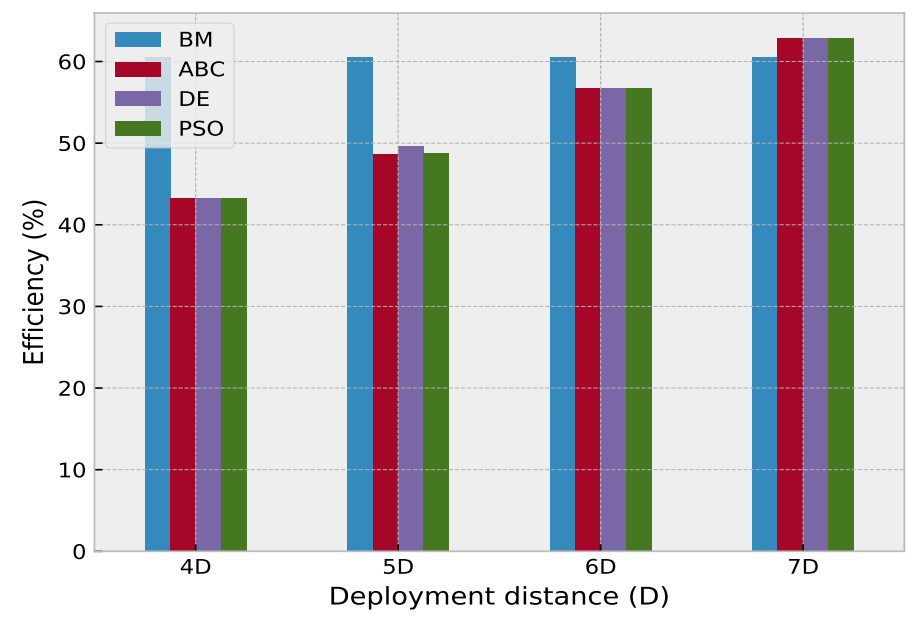

Figure 18. Plant efficiency variation for a $7 \mathrm{~m} / \mathrm{s}$ inflow. 


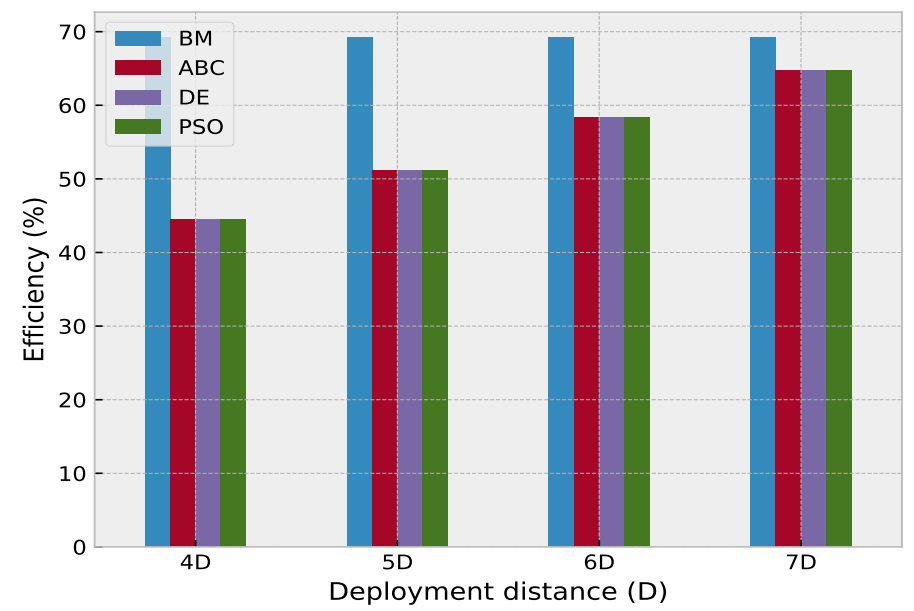

Figure 19. Plant efficiency variation for a $8 \mathrm{~m} / \mathrm{s}$ inflow.

\section{Discussion}

As with other studies in literature that employ static models where the power is modeled using static $C_{p}$ or $a$ tables, it is assumed that the wind direction is constant for the duration of the measurement and optimization, with axial induction set-points adjusting as wind direction changes, to maintain maximal plant power. As noted in Reference [45], in order to obtain a power increase, power derating for upstream turbines are enforced when the wind direction produces the minimum T-2-T distance, with all turbines returning to base case operations for directions with large T-2-T distances. Given the fact that only one wind direction was studied $(\mathcal{B}=1)$, and the annual energy production or power production over any arbitrary period (energy production) was not considered, the gains afforded by employing this deployment strategy was not evident. Notwithstanding, gains afforded by combining this deployment strategy with a TI-constrained axial inductionbased power maximization are observed.

Results in Figures 6-9 and in Table 7 suggests that, at a low inflow of $7 \mathrm{~m} / \mathrm{s}$, the studied schemes can provide an overall plant power increase of up to $37 \%$ with $4 D$ deployments, with this increment decreasing to about $22 \%$ for a $5 D$ deployment and further down to approximately $10 \%$ with a $6 D$ deployment. Not only does this clearly highlight the benefits of employing the studied algorithms to optimize the system, it also validates the fact that turbine density increments can yield power density increments without compromising the loading on turbines which are evident in the TI levels experienced at these turbines. As demonstrated in Figures 9 and 10 and in Table 7, an increase in the inflow decreases how much gain can be obtained through system optimization, with gains dropping from $37.4 \%$ to $6.31 \%$ for $4 D, 22.1 \%$ to $3.69 \%$ for $5 D, 9.9 \%$ to $-0.35 \%$ for $6 D$, and $3.95 \%$ to $-7.24 \%$ for the $7 D$ deployment. Table 8 contains results of comparison between the optimized $4 D, 5 D$, and $6 D$ deployments with the benchmark $7 D$ deployment in its optimized and non-optimized forms. As expected, it confirms the fact that power density increments decrease with increasing deployment distance as less turbines would be able to fit into the fixed plant area when the deployment distance is increased. As shown in Table 8, overall plant power at $7 \mathrm{~m} / \mathrm{s}$ inflow obtained from the optimized $4 D$ deployment surpasses the optimized and non-optimized benchmark deployment by as much as $47.1 \%$ and $48.9 \%$, respectively. This table also confirms, as already established, a drop in power gains as deployment distance is increased. It should be noted that Table 7 presents a comparison between MWZ/plant power (optimized and Base case), where both instances are equally populated with the same number of turbines. However, Table 8 compares plant power between the densely populated $4 D, 5 D$, and $6 D$ deployments and the lightly populated $7 D$ deployment (due to its large T-2-T separation distance). Hence, larger power gains are experienced in the latter compared to the former because the latter is a combination of gains from system optimization and turbine density increment. In terms of TI levels, all 
schemes sufficiently manage TI effects originating from increased turbine density, keeping it below the recommended $20 \%$, as shown in Table 7 .

Besides the wake interactions and restrictions imposed on turbines due to turbulence intensity levels, factors, such as the ground surface roughness, can also affect the extent of wake recovery. This has the capacity of increasing or decreasing the deficit, depending on the T-2-T distance, and could reduce the gains reported for the close T-2-T deployments. It is also possible that surrounding atmospheric conditions, such as temperature and pressure gradients, over the height of the rotor surface, can affect the air density and, hence, the increments or decrements in power thereof.

Figures 18 and 19 show that plant efficiency is compromised due to increased wake deficits caused by turbine density increment. This decrease in efficiency is seen to worsen with increasing wind inflow. The efficiency metric may be of interest to an investor, but may not be of that much importance to a farm planner who is more concerned with increasing the annual energy production (AEP) of the plant, a metric that can only be improved through a combination of power density increment (from turbine density increment) and application of plant-wide optimization. Several factors can affect a plant planner's decision to increase turbine density, and these could include access to land space with attractive wind resource, as well as unwillingness of the land owners or community to sell such. It can also be caused by the need to improve proximity to individual turbines. All these limiting factors have an impact on the capital expenditure (CAPEX) of the wind plant and enforce an increase in turbine density within a limited available or restricted land space.

In this study, only three inflow conditions within the turbine's operating range have been considered. It is also possible that, although the $4 D$ deployments produce large overall plant power gains compared to the $7 D$ baseline deployments, at much lower inflows closer to $U_{i n}$, there will be turbines further behind in a MWZ that will have insufficient wind speed to generate power because there is insufficient distance to allow the wakes to recover. So, as attractive as the results may seem, such deployments may not be realistic given that a wind farm planner's desire will be that all or most turbines are productive all the time, especially at wind inflows with high probability of occurrence, thus improving plant efficiency.

\section{Conclusions}

In this study, the superposition method for a kinematic wake model has been redefined due to the close T-2-T distances employed. Coupled with Frandsen's simplified wake turbulence model, power productions and turbulence levels at turbines in a hypothetical wind plant have been modeled. To intentionally improve power density through turbine density increment, closer T-2-T deployments were studied and compared with a baseline $7 D$ deployment, a deployment distance that according to literature is assumed standard to reduce wake interactions.

Applying particle swarm optimization (PSO), artificial bee colony (ABC), and differential evolution (DE) optimization algorithms, individual turbine power productions have been controlled cooperatively using a TI-constrained axial induction-based optimization. With this strategy, an overall maximized wind plant power is obtained, and rising TI levels at each turbine caused by an increase in turbine density are controlled and maintained below the set maximum $\left(T I^{\max }\right)$. All three algorithms are almost equally impressive in their performances. Comparing corresponding deployments, obtained results show that plant power gains of up to $37 \%$ are possible with optimization at $7 \mathrm{~m} / \mathrm{s}$ for tightly spaced $4 D$ deployments, with this gain decreasing with increasing deployment distance and increasing wind inflow. In comparison with the benchmark $7 D$ deployment, power gains of up to $48 \%$ are possible with an optimized $4 D$ deployment at a $7 \mathrm{~m} / \mathrm{s}$ inflow. As expected, this gain margin in comparison to the benchmark is shown to decrease as deployment distance increases. The investigated wind inflow values fall within the range of realistic wind speed values with a high frequency of occurrence. Given that the wind speed distribution for most sites, including the site under study (whose wind rose and wind speed distribution is given in Appendix A section), 
are positively skewed, this means that the lower wind speeds have a higher frequency of occurrence. Hence, given the impressive plant power gains demonstrated by this study, and considering that plant power increments decrease with increasing wind inflow, an efficient application of this control strategy at these frequently occurring wind speeds may result in an improved annual energy production AEP for the site.

By considering three different wind conditions, the study has shown how the maximized wind plant power varies with increasing wind inflow. Generally, it is observed that obtained plant power gains decrease with increasing wind inflow and with increasing deployment distance. This validates the decision in literature to assume large deployment distances, such as the 7D deployment used in this study, as standard (not deserving of turbine set-point optimization). This is because such is likely to yield no overall plant power improvement, hence a waste of computational resources and communication bandwidth in dissemination of such set-point updates in smart wind plant scenarios.

Future study will incorporate ground surface roughness to the wake model and study its effects. Given that a mean wind inflow increase causes a decrease in the overall plant power increments, future study will investigate the effects that optimizing over the entire operating range of a MW turbine will have on the AEP of the wind plant, considering the probabilities of occurrence of each mean wind inflow and direction.

Author Contributions: Conceptualization, M.C., D.T.O.O. and M.D.; methodology, M.C.; software, M.C.; validation, M.C. and D.T.O.O.; formal analysis, M.C., D.T.O.O. and M.D.; investigation, M.C.; resources, M.C., D.T.O.O. and M.D.; data curation, M.C., D.T.O.O. and M.D.; writing-original draft preparation, M.C.; writing-review and editing, M.C., D.T.O.O. and M.D.; visualization, M.C.; supervision, D.T.O.O. and M.D.; project administration, M.C., D.T.O.O. and M.D.; funding acquisition, M.C. All authors have read and agreed to the published version of the manuscript.

Funding: This research was funded in part by the Petroleum Technology Development Fund (PTDF) Nigeria and Italy-South Africa Joint Research Programme (ISARP) grant through the National Research Foundation (NRF) South Africa.

Institutional Review Board Statement: Not applicable.

Informed Consent Statement: Not applicable.

Data Availability Statement: Wind data used for the analysis and plots in the Appendix A section can be found online at http:/ / wasadata.csir.co.za/wasa1/WASAData, accessed on 18 July 2021.

Acknowledgments: Special thanks go to Stephen Ekwe, Sunday Oladejo, and Lateef Akinyemi for their technical discussions and exchange of thoughts regarding this study especially with the optimization algorithms. I also acknowledge the all-round support of the Power Systems Research Group and the Center for Broadband Networks, Department of Electrical Engineering, University of Cape Town.

Conflicts of Interest: The authors declare no conflict of interest.

$\begin{array}{ll}\text { Abbreviations } \\ \text { IEC } & \text { International Electrotechnical Commission } \\ \text { WT } & \text { Wind Turbine } \\ \text { TI } & \text { Turbulence Intensity } \\ \text { PSO } & \text { Particle Swarm Optimization } \\ \text { ABC } & \text { Artificial Bee Colony } \\ \text { DE } & \text { Differential Evolution } \\ \text { T-2-T } & \text { Turbine-to-turbine } \\ \text { MWZ } & \text { Major Wake Zone } \\ \text { Base } & \text { Base case scenario } \\ \text { BM } & \text { Benchmark scenario }\end{array}$




\section{Appendix A}

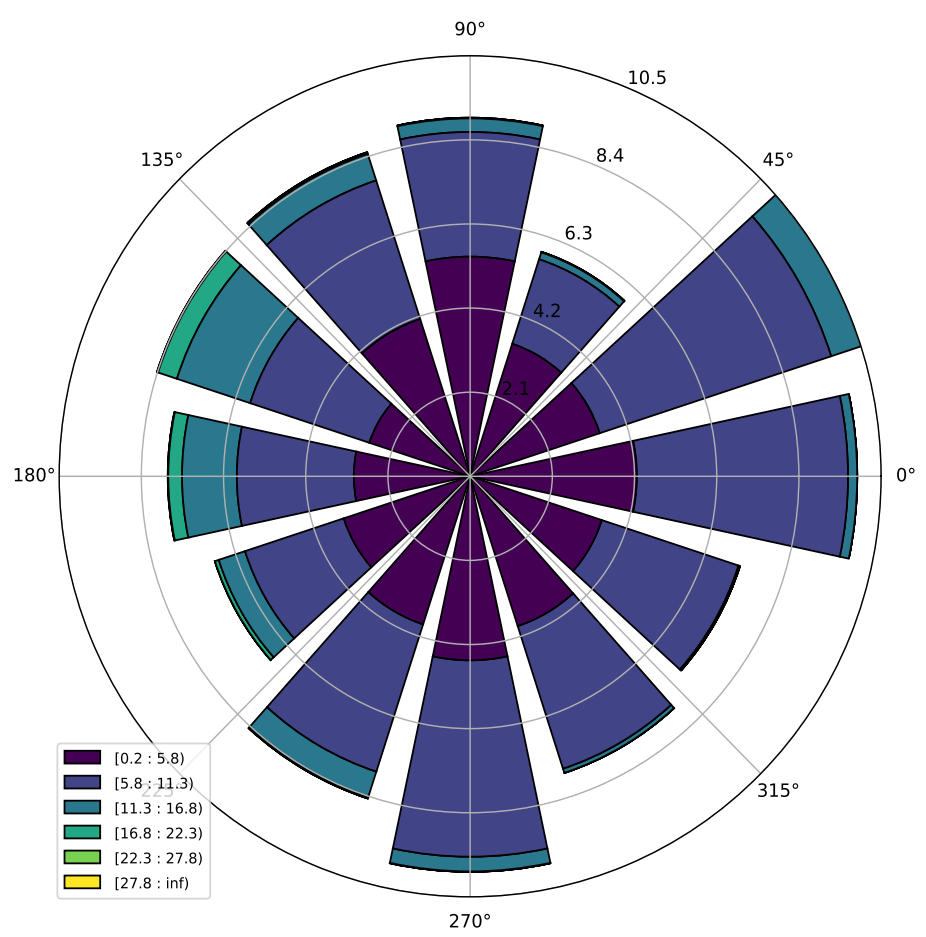

Figure A1. Twelve-bin wind rose for WM10 Butterworth at $60 \mathrm{~m}$ above ground level.

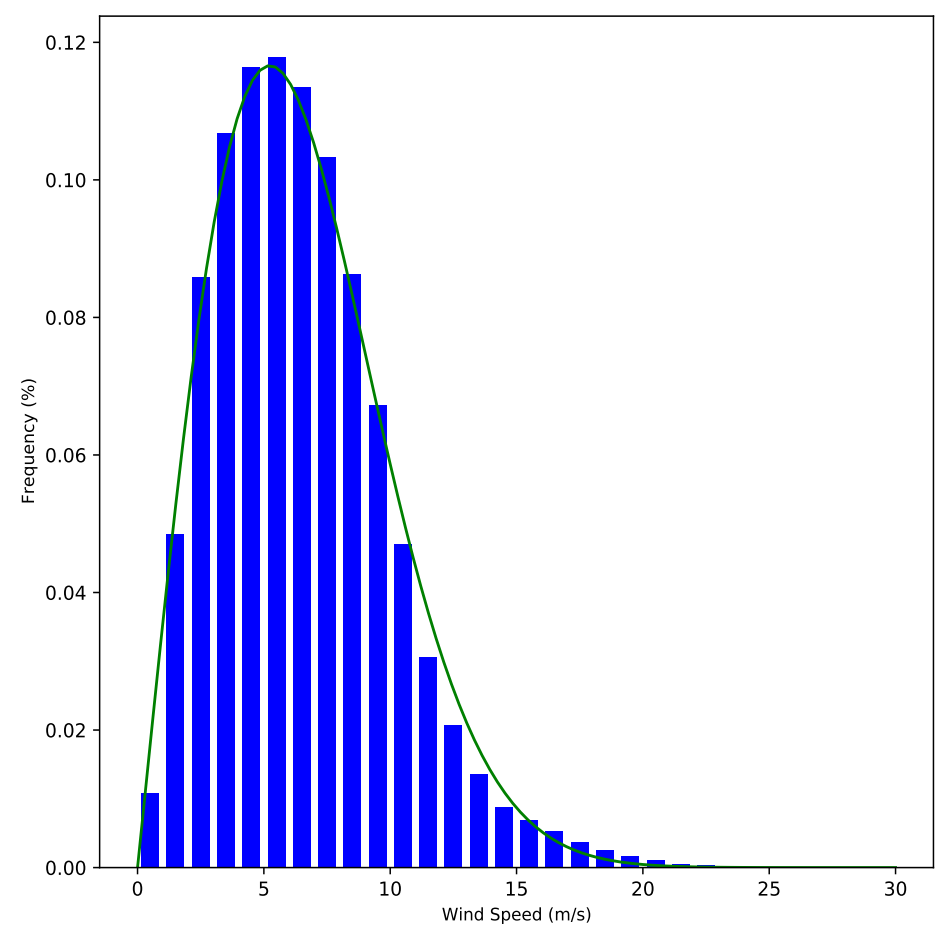

Figure A2. Wind speed distribution for WM10 Butterworth at $60 \mathrm{~m}$ above ground level.

Butterworth is a town in the Eastern Cape province of South Africa. The wind data, as shown, represents a 2-year period from March 2011 to February 2012 and October 2012 to December 2013. 


\section{References}

1. Joyce, L.; Feng, Z. GWEC-Global-Wind-Report-2021. 2021. Available online: https://gwec.net/global-wind-report-2021/ (accessed on 17 May 2021).

2. Ahmad, T.; Coupiac, O.; Petit, A.; Guignard, S.; Girard, N.; Kazemtabrizi, B.; Matthews, P.C. Field implementation and trial of coordinated control of wind farms. IEEE Trans. Sustain. Energy 2017, 9, 1169-1176. [CrossRef]

3. Qian, G.W.; Ishihara, T. Wind farm power maximization through wake steering with a new multiple wake model for prediction of turbulence intensity. Energy 2021, 220, 119680. [CrossRef]

4. Niayifar, A.; Porté-Agel, F. Analytical modeling of wind farms: A new approach for power prediction. Energies 2016, 9, 741. [CrossRef]

5. Chowdhury, S.; Zhang, J.; Messac, A.; Castillo, L. Optimizing the arrangement and the selection of turbines for wind farms subject to varying wind conditions. Renew. Energy 2013, 52, 273-282. [CrossRef]

6. Bossanyi, E.; Jorge, T. Optimisation of wind plant sector management for energy and loads. In Proceedings of the 2016 European Control Conference (ECC), Aalborg, Denmark, 29 June-1 July 2016; pp. 922-927.

7. Katic, I.; Højstrup, J.; Jensen, N.O. A simple model for cluster efficiency. In Proceedings of the European Wind Energy Association Conference and Exhibition, Rome, Italy, 7-9 October 1986; Volume 1, pp. 407-410.

8. Lissaman, P. Energy effectiveness of arbitrary arrays of wind turbines. J. Energy 1979, 3, 323-328. [CrossRef]

9. Frandsen, S. On the wind speed reduction in the center of large clusters of wind turbines. J. Wind. Eng. Ind. Aerodyn. 1992, 39, 251-265. [CrossRef]

10. Abkar, M.; Porté-Agel, F. The effect of free-atmosphere stratification on boundary-layer flow and power output from very large wind farms. Energies 2013, 6, 2338-2361. [CrossRef]

11. Argyle, P.; Watson, S.; Montavon, C.; Jones, I.; Smith, M. Modelling turbulence intensity within a large offshore wind farm. Wind Energy 2018, 21, 1329-1343. [CrossRef]

12. Schepers, J. ENDOW: Validation and Improvement of ECN's Wake Model; Energy Research Centre of the Netherlands ECN; Office of Scientific and Technical Information (OSTI); U.S. Department of Energy: Oak Ridge, TN, USA, 2003.

13. Gribben, B.; Williams, N.; Ranford, D. Offshore wind farm layout design-A systems engineering approach. In Proceedings of the Ocean Power Fluid Machinery, London, UK, 2010; Volume 19. Available online: https:/ / citeseerx.ist.psu.edu/viewdoc/ download?doi=10.1.1.738.4465\&rep=rep1\&type=pdf (accessed on 1 August 2021).

14. Gebraad, P.; Thomas, J.J.; Ning, A.; Fleming, P.; Dykes, K. Maximization of the annual energy production of wind power plants by optimization of layout and yaw-based wake control. Wind Energy 2017, 20, 97-107. [CrossRef]

15. Fleming, P.A.; Ning, A.; Gebraad, P.M.; Dykes, K. Wind plant system engineering through optimization of layout and yaw control. Wind Energy 2016, 19, 329-344. [CrossRef]

16. Charles, M.; Oyedokun, D.T.; Dlodlo, M. Wind Farm Density Effects on Turbulence Intensity for Large Hexagonal Farm Arrays. In Proceedings of the 2020 6th IEEE International Energy Conference (ENERGYCon), Gammarth, Tunisia, 28 September1 October 2020; pp. 1-6.

17. Johnson, K.E.; Thomas, N. Wind farm control: Addressing the aerodynamic interaction among wind turbines. In Proceedings of the 2009 American Control Conference, St. Louis, MO, USA, 10-12 June 2009; pp. 2104-2109.

18. Van der Hoek, D.; Kanev, S.; Allin, J.; Bieniek, D.; Mittelmeier, N. Effects of axial induction control on wind farm energy production-a field test. Renew. Energy 2019, 140, 994-1003. [CrossRef]

19. Bartl, J.; Sætran, L. Experimental testing of axial induction based control strategies for wake control and wind farm optimization. J. Phys. Conf. Ser. 2016, 753, 032035. [CrossRef]

20. Wu, Y.K.; Lee, C.Y.; Chen, C.R.; Hsu, K.W.; Tseng, H.T. Optimization of the wind turbine layout and transmission system planning for a large-scale offshore windfarm by AI technology. IEEE Trans. Ind. Appl. 2013, 50, 2071-2080. [CrossRef]

21. Munters, W.; Meyers, J. Dynamic strategies for yaw and induction control of wind farms based on large-eddy simulation and optimization. Energies 2018, 11, 177. [CrossRef]

22. Rahmani, R.; Khairuddin, A.; Cherati, S.M.; Pesaran, H.M. A novel method for optimal placing wind turbines in a wind farm using particle swarm optimization (PSO). In Proceedings of the 2010 Conference Proceedings IPEC, Suntec, Singapore, 27-29 October 2010; pp. 134-139.

23. Kefayat, M.; Ara, A.L.; Niaki, S.N. A hybrid of ant colony optimization and artificial bee colony algorithm for probabilistic optimal placement and sizing of distributed energy resources. Energy Convers. Manag. 2015, 92, 149-161. [CrossRef]

24. Pookpunt, S.; Ongsakul, W. Optimal placement of wind turbines within wind farm using binary particle swarm optimization with time-varying acceleration coefficients. Renew. Energy 2013, 55, 266-276. [CrossRef]

25. Ahmad, T.; Girard, N.; Kazemtabrizi, B.; Matthews, P.C. Analysis of Two Onshore Wind Farms with a Dynamic Farm Controller. In Proceedings of the EWEA 2015, Paris, France, 17-20 November 2015.

26. Ahmad, T.; Matthews, P.; Kazemtabrizi, B. PSO based wind farm controller. In Proceedings of the Eurogen Conference 2015, Glasgow, UK, 14-16 September 2015.

27. Gionfra, N.; Sandou, G.; Siguerdidjane, H.; Faille, D.; Loevenbruck, P. Wind farm distributed PSO-based control for constrained power generation maximization. Renew. Energy 2019, 133, 103-117. [CrossRef]

28. Wan, C.; Wang, J.; Yang, G.; Gu, H.; Zhang, X. Wind farm micro-siting by Gaussian particle swarm optimization with local search strategy. Renew. Energy 2012, 48, 276-286. [CrossRef] 
29. Massan, S.U.R.; Wagan, A.I.; Shaikh, M.M.; Shah, M.S. Application of differential evolution for wind turbine Micrositing. Mehran Univ. Res. J. Eng. Technol. 2017, 36, 353-366. [CrossRef]

30. Osuna-Enciso, V.; Espinoza-Haro, J.I.; Oliva, D.; Hernández-Ahuactzi, I.F. Offshore wind farm layout optimization via differential evolution. Comput. Sist. 2018, 22, 929-941. [CrossRef]

31. Long, H.; Li, P.; Gu, W. A data-driven evolutionary algorithm for wind farm layout optimization. Energy 2020, 208, 118310. [CrossRef]

32. Yin, P.Y.; Li, G.S. A Hyper-Heuristic of Artificial Bee Colony and Simulated Annealing for Optimal Wind Turbine Placement. In Proceedings of the International Conference on Swarm Intelligence, Shanghai, China, 17-22 June 2018; Springer: Cham, Switzerland, 2018; pp. 145-152.

33. Sanderse, B. Aerodynamics of Wind Turbine Wakes-Literature Review; ECN Wind Energy: Petten, The Netherlands, 2009.

34. Heris, M.K. Particle Swarm Optimization (PSO) in Python. 2020. Available online: https://yarpiz.com/463/ypea127-pso-inpython) (accessed on 17 May 2021).

35. Tungom, C.E. Artificial Bee Colony (ABC) Algorithm with Python. 2017. Available online: https://github.com/ChiaT27/ Artificial-Bee-Colony-Optimization (accessed on 17 May 2021).

36. Manwell, J.F.; McGowan, J.G.; Rogers, A.L. Wind Energy Explained: Theory, Design and Application; John Wiley \& Sons: Hoboken, NJ, USA, 2010.

37. Betz, A. Introduction to the Theory of Flow Machines; Elsevier: Amsterdam, The Netherlands, 2014.

38. Zong, H.; Porté-Agel, F. A momentum-conserving wake superposition method for wind farm power prediction. J. Fluid Mech. 2020, 889, A8. [CrossRef]

39. Porté-Agel, F.; Bastankhah, M.; Shamsoddin, S. Wind-turbine and wind-farm flows: A review. Bound.-Layer Meteorol. 2020, 174, 1-59. [CrossRef] [PubMed]

40. Voutsinas, S.; Rados, K.; Zervos, A. On the analysis of wake effects in wind parks. Wind. Eng. 1990, 14, $204-219$.

41. Park, J.; Law, K.H. Layout optimization for maximizing wind farm power production using sequential convex programming. Appl. Energy 2015, 151, 320-334. [CrossRef]

42. Shakoor, R.; Hassan, M.Y.; Raheem, A.; Wu, Y.K. Wake effect modeling: A review of wind farm layout optimization using Jensen's model. Renew. Sustain. Energy Rev. 2016, 58, 1048-1059. [CrossRef]

43. Van Dam, F.; Gebraad, P.; van Wingerden, J.W. A maximum power point tracking approach for wind farm control. In Proceedings of the Science of Making Torque from Wind, Oldenburg, Germany, 9-11 October 2012; Volume 103.

44. WAsP Wind Assesment Program. Available online: https://www.wasp.dk/wasp\#educational-wasp (accessed on 15 June 2018 ).

45. Knudsen, T.; Bak, T.; Svenstrup, M. Survey of wind farm control-Power and fatigue optimization. Wind Energy 2015, 18, 1333-1351. [CrossRef] 